\author{
UNIVERSIDADE DE SÃO PAULO \\ FACULDADE DE FILOSOFIA, CIÊNCIAS E LETRAS DE \\ RIBEIRÃO PRETO \\ DEPARTAMENTO DE FÍSICA E MATEMÁTICA
}

RAÚL ERNESTO CAMARGO MENDOZA

DETERMINAÇÃO DE GRANDEZAS DOSIMÉTRICAS DE INTERESSE EM MAMOGRAFIA USANDO DETECTORES TERMOLUMINESCENTES

RIBEIRÃO PRETO - SP 


\section{RAÚL ERNESTO CAMARGO MENDOZA}

\section{DETERMINAÇÃO DE GRANDEZAS DOSIMÉTRICAS DE INTERESSE EM MAMOGRAFIA USANDO DETECTORES TERMOLUMINESCENTES}

Dissertação submetida ao Programa de Pós-Graduação em Física Aplicada à Medicina e Biologia da Faculdade de Filosofia Ciências e Letras de Ribeirão Preto, da Universidade de São Paulo, como requisito parcial para obtenção do título de Mestre em Ciências.

Orientador: Prof. Dr. Martín Eduardo Poletti.

\section{RIBEIRÃO PRETO - SP}


AUTORIZO A REPRODUÇÃO E DIVULGAÇÃO TOTAL OU PARCIAL DESTE TRABALHO POR QUALQUER MEIO CONVENCIONAL OU ELETRÔNICO, PARA FINS DE ESTUDO E PESQUISA, DESDE QUE CITADA A FONTE.

\section{Camargo Mendoza, Raúl Ernesto}

Determinação de grandezas dosimétricas de interesse em mamografia usando detectores termoluminescentes/Raúl E. Camargo M.; Orientação: Prof. Dr. Martin Eduardo Poletti, Ribeirão Preto: FFCLRP / USP, 2010.

Dissertação (Mestrado) apresentada à Faculdade de Filosofia, Ciências e Letras de Ribeirão Preto - Universidade de São Paulo.

1. Dose de Entrada na Pele

3. Dose em Profundidade

2. Fator de Retroespalhamento 


\section{Agradecimentos}

Agradeço a Deus por ter assegurado minhas mãos e abençoado minha vida em todo momento, e por me levar sempre pelo caminho certo; pela família e os amigos meus torcedores incondicionais, e pelas oportunidades concedidas

Ao Professor Dr. Martín Eduardo Poletti, meu orientador, pela oportunidade de fazer parte de seu grupo de trabalho, por sua valiosa orientação no desenvolvimento deste projeto, e pela oportunidade concedida para fazer este mestrado.

Ao Professor Dr. Alexandre Souto Martínez, pelo seu apoio incondicional, e por me ajudar a ter a oportunidade de estudar na USP.

À valiosa ajuda de minha família, especialmente minha mãe Sari, meu pai Raúl, e minhas irmãs Taidé e Sary, não tenho vida suficiente para agradece-les.

À Andrea Beatriz e Ana Sofía, minhas filhas, muito obrigado pela sua generosidade $\mathrm{e}$ amor incondicional por seu pai, assim também para a Ana Cecília, obrigado por tudo, minha divida é eterna com você.

Aos meus caros amigos Adolfo e Rigoberto pela confiança e valiosa ajuda.

Ao Kairo, para quem nunca encontrarei as palavras adequadas para agradece - le toda sua hospitalidade e amizade.

À Maria Cristina quero agradecer por suas permanentes palavras para me animar e pelos momentos inesquecíveis compartilhados.

Ao Professor Dr. Thomas Ghiliardi Neto, por toda sua colaboração e ajuda no Hospital das Clínicas.

Ao Marco Aurélio e Vilma por sua valiosa colaboração e amizade, assim como a Lucia, Marta e Marileni por toda sua ajuda e paciência.

À Professora Dra. Patrícia Nicolucci por toda sua valiosa e inesquecível ajuda.

Ao pessoal do CIDRA, especialmente a Cassiana, Eliana, Márcia, Simone, Silvana, Claudia, Mariela e o Daniel, por sua paciência e ajuda.

Ao Professor Dr. Alessandro Martins Da Costa pela sua valiosa colaboração e confiança em mim.

Ao Mairon, Fabio, Jorge, Rondi, Gustavo, Ariadne, e Carmen pela ajuda e os bons momentos compartilhados. 
À Alessandra pela sua orientação e opiniões enriquecedoras, assim como ao grupo de Física das Radiações e Dosimetria.

Quero agradecer especialmente ao técnico José Luiz Aziani por todos seus serviços e especialmente por sua amizade, assim como ao Élcio Aparecido Neves, Lourenço Rocha, Sergio Oliveira, Adriano de Jesus Holanda, Adriano, Fabio José Morati e Everton por toda sua colaboração.

A todos os amigos maravilhosos que muito ajudaram na obtenção deste mestrado, muito especialmente ao Raimundo Nonato, Felipe, e Bené, eles fizeram desta experiência brasileira, uma vivência inesquecível, muito obrigado.

Ao IFARHU e SENACYT, as instituições panamenhas através das quais o estado forneceu a bolsa de mestrado, com uma especial distinção a minha boa amiga Itzel Hubbard, chefa da seção de bolsas internacionais do IFARHU.

À Clélia, muito obrigado pela ajuda fundamental para a finalização deste trabalho.

À Sandra, muito obrigado por sua oportuna, desinteressada e fundamental ajuda para que eu conseguisse viajar ao Brasil.

Finalmente, e não por isso menos importante, ao nobre e generoso povo panamenho pela oportunidade para este seu humilde filho, que espera retribuir toda confiança depositada nele, e ao grande povo do Brasil por toda sua hospitalidade, calor humano, generosidade, e por me fazer sentir neste período como mais um filho desta terra abençoada por Deus. 
À Ana Sofía e Andrea Beatriz 


\section{SUMÁRIO}

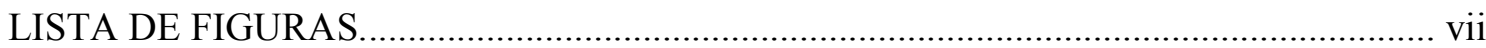

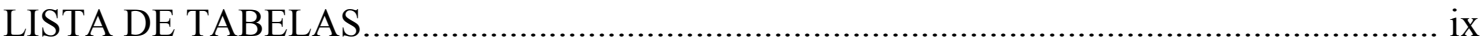

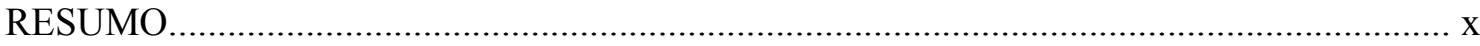

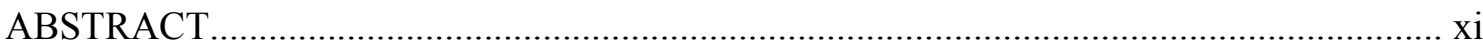

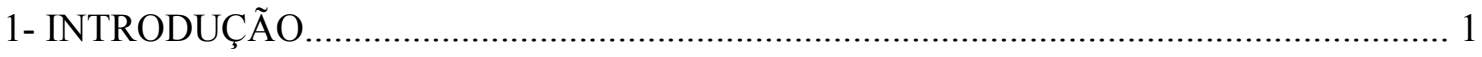

2- MATERIAIS E MÉTODOS..................................................................................... 5

2.1 - Dosímetros Termoluminescentes de Fluoreto de Lítio................................................. 5

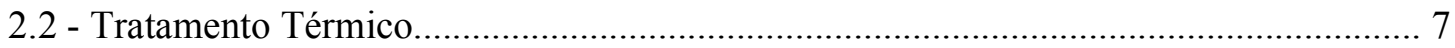

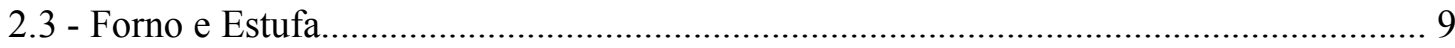

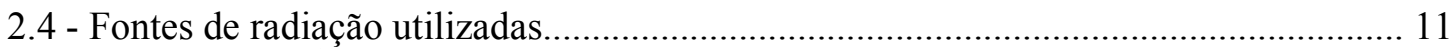

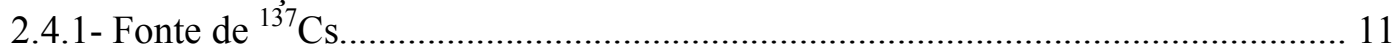

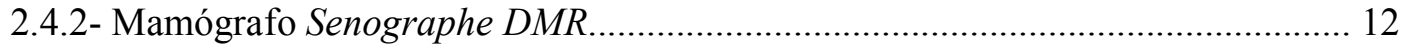

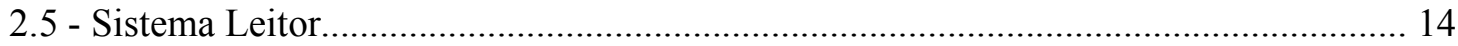

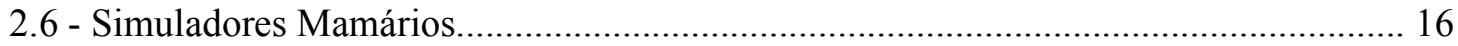

2.7 - Caracterização e Calibração dos dosímetros TLD-100 ................................................. 18

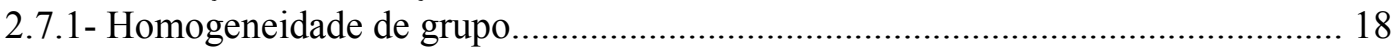

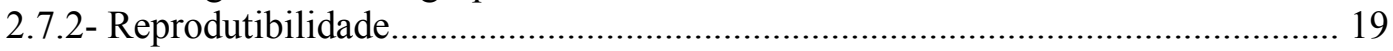

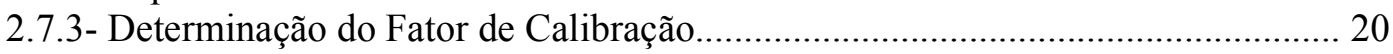

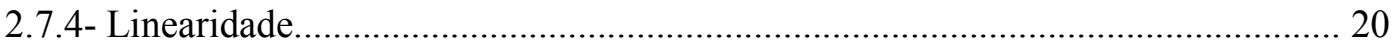

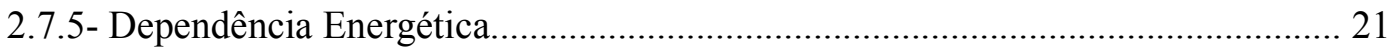

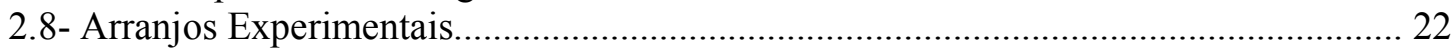

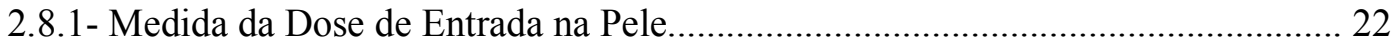

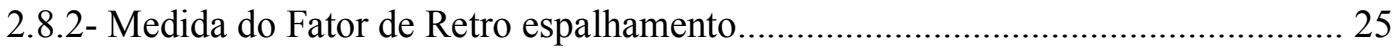

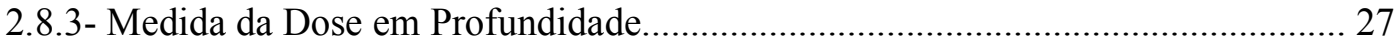

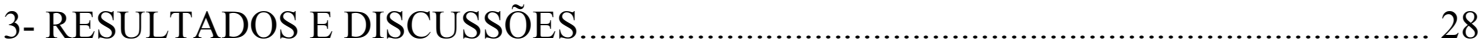

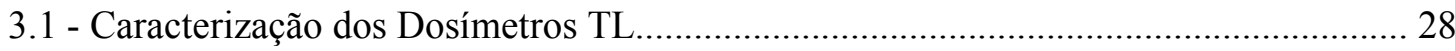

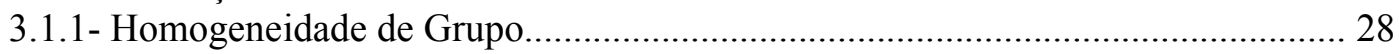

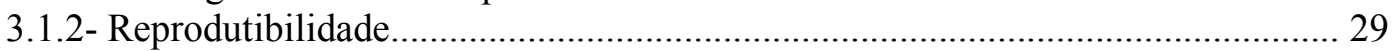

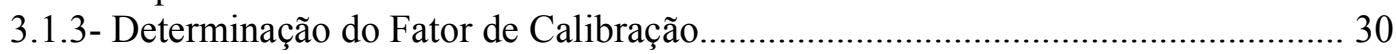

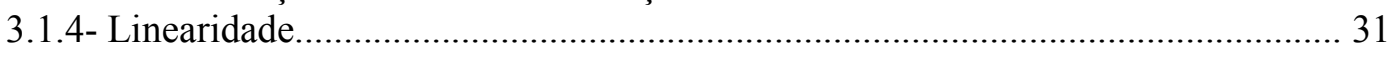

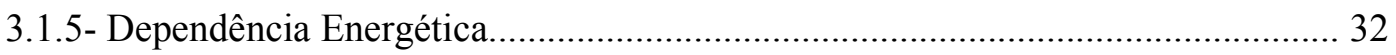

3.2 - Determinação da Dose de Entrada na Pele..................................................................... 33

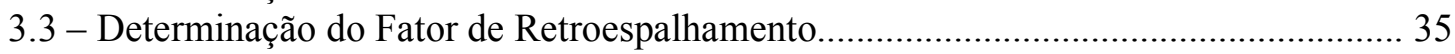

3.3.1- Fator de Retroespalhamento: Dependências Geométricas................................... 36

3.3.1.1- Fator de Retroespalhamento em função da espessura do simulador mamário ............................................................................................ 36

3.3.1.2- Fator de Retroespalhamento em função do tamanho da área

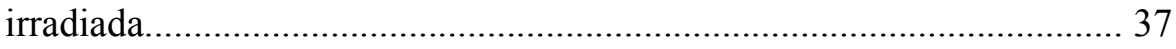


3.3.1.3- Fator de Retroespalhamento em função da distancia foco- superfície...... 38

3.3.2- Fator de Retro espalhamento: Dependências Energéticas.................................. 39

3.3.2.1- Fator de Retroespalhamento em função da Camada Semi-redutora......... 39

3.3.2.2- Fator de Retroespalhamento em função da Combinação Ánodo-Filtro.... 42

3.3.2.3 - Fator de Retroespalhamento em função da Tensão do Mamógrafo........... 43

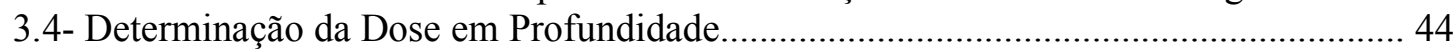

3.4.1 - Dose em Profundidade em função da Tensão do Mamógrafo............................... 44

3.4.2- Dose em Profundidade em função da Combinação Ánodo-Filtro......................... 45

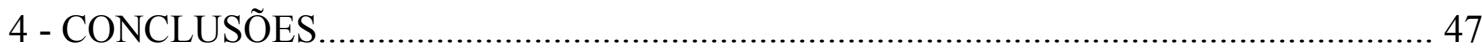

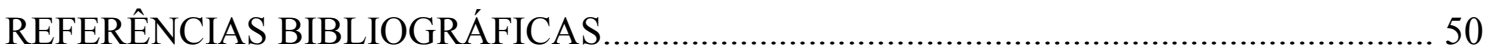




\section{LISTA DE FIGURAS}

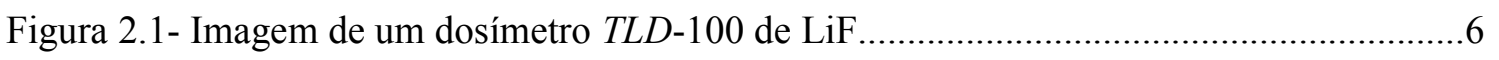

Figura 2.2- Forno empregado para fazer o tratamento térmico pré-irradiação........................ 10

Figura 2.3- Estufa utilizada para o tratamento térmico dos $T L D$ s........................................ 10

Figura 2.4- Imagem do suporte para o posicionamento da fonte de ${ }^{137} \mathrm{Cs}$ e dos suporte

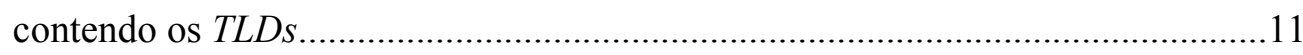

Figura 2.5- Mamógrafo Senographe DMR $(G E \AA)$ do Hospital das Clínicas-USP RP............ 12

Figura 2.6- a- Câmara de Ionização para mamografia 10X5-6M

b- Eletrômetro 9015 RM-S .......................................................................... 13

Figura 2.7- Partes básicas do Sistema Leitor de Termoluminescência................................... 14

Figura 2.8- Sistema Leitor:

a.Modulo A contendo a prancheta e o tubo fotomultiplicador.

b.Modulo B integrador do sinal TL contendo o "display".................................. 15

Figura 2.9- Simuladores mamários:

a-Semicilíndrico de $10 \mathrm{~cm}$ de radio

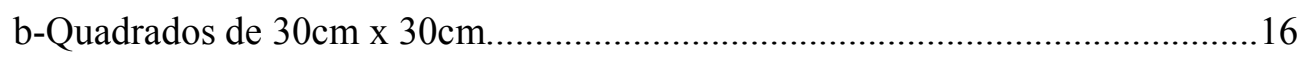

Figura 2.10- Arranjo experimental para a determinação da $D E P$........................................ 24

Figura 2.11- Esquema da medida da dose:

a) sem o tecido espalhador.

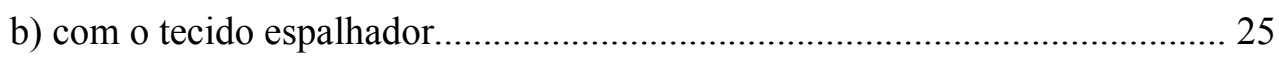

Figura 2.12- Arranjo experimental usado para irradiar os dosímetros na condição "sem tecido espalhador"............................................................................ 26

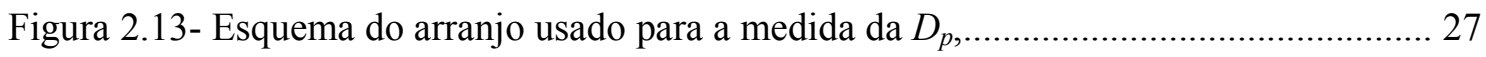

Figura 3.1 - Curva de Resposta TL em função da Dose........................................................ 32

Figura 3.2- Resposta Relativa em função da energia do feixe.............................................. 33

Figura 3.3- DEP como função da CSR para um simulador mamário de PMMA de $6 \mathrm{~cm}$ de espessura...

Figura 3.4- DEP como função da espessura para diferentes valores de tensão do tubo, e o

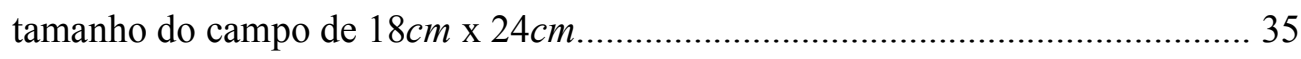

Figura 3.5- BSF vs espessura do simulador mamário para todas as combinações ânodo-filto, campo de $18 \mathrm{~cm}$ x $24 \mathrm{~cm}$ e $28 \mathrm{kV}$ 36 
Figura 3.6- $B S F$ como função do tamanho do campo de radiação, para simuladores semicilíndricos e de $30 \mathrm{~cm} \times 30 \mathrm{~cm}$ de PMMA com espessura de $4 \mathrm{~cm}$.

Figura 3.7- BSF como função da distancia foco-superficie. Usando uma combinação Mo-Mo, simulador de $4 \mathrm{~cm}$ de espessura, campo de $18 \mathrm{~cm} \times 24 \mathrm{~cm}$, e $28 \mathrm{kV} \ldots \ldots . . .38$

Figura 3.8- BSF vs CSR para todas as espessuras, combinação Mo-Mo e campo

$18 \mathrm{~cm} \times 24 \mathrm{~cm}$ 40

Figura 3.9- $B S F$ vs CSR, comparação entre os resultados obtidos neste trabalho as referências bibliográficas. 41

Figura 3.10- BSF como função da combinação ânodo-filtro, para simulador semicilindricos de $6 \mathrm{~cm}$ de espessura, $32 \mathrm{kVp}$ no tubo e campos de $9 \mathrm{~cm} \times 9 \mathrm{~cm}$ e $18 \mathrm{~cm} \times$ $24 \mathrm{~cm}$ 42

Figura 3.11- $B S F$ como função do $\mathrm{kVp}$ do tubo de raios x, combinação Mo-Mo, simulador de $4 \mathrm{~cm}$ de espessura e campo de $18 \mathrm{~cm} \times 24 \mathrm{~cm}$.. 43

Figura 3.12- Dose como função da profundidade variando os valores da tensão do tubo. 45

Figura 3.13- Dose como função da profundidade para as diferentes combinações ânodofiltro. 


\section{LISTA DE TABELAS}

Tabela 2.1- Temperaturas e tempos das etapas do Tratamento Térmico................................. 9

Tabela 2.2- Simulador de mamas típicas em mulheres de 50 até 64 anos de idade usando blocos de PMMA..................................................................... 17

Tabela 3.1- Resultado do cálculo do coeficiente de variação (CV)....................................... 29

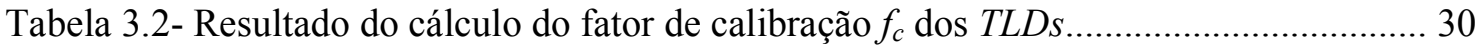




\section{RESUMO}

CAMARGO MENDOZA, R.E. Determinação de Grandezas Dosimétricas de interesse em Mamografía usando Detectores Termoluminescentes. [Dissertação]. Ribeirão Preto: Faculdade de Filosofia Ciências e Letras de Ribeirão Preto, Universidade de São Paulo; 2010. $66 \mathrm{p}$.

Os órgãos de saúde internacionais e nacionais, como o Ministério da Saúde na portaria 453/98 da Vigilância Sanitária, exigem que a Dose de Entrada na Pele seja avaliada para cada equipamento mamográfico através da leitura de um sistema câmara de ionização-eletrómetro corrigida pelo fator de retroespalhamento. Ao não existir menção explícita na portaría de valores utilizáveis para o fator de retroespalhamento, este trabalho visa à determinação experimental do fator de retroespalhamento, através da utilização dos dosímetros termoluminescentes $T L D-100$. No estudo são verificadas as dependências geométricas e espectrais do fator de retroespalhamento, assim como do valor da Dose de Entrada na Pele, e da Dose em Profundidade, correspondentes com as técnicas radiográficas empregadas nos exames mamográficos convencionais de rotina. Foram avaliados feixes na faixa de 0,35 $m m \mathrm{Al}$ até $0,43 m m \mathrm{Al}$, tensões do tubo de $25 \mathrm{kV}, 28 \mathrm{kV}, 30 \mathrm{kV}$, e $32 \mathrm{kV}$, assim como os três tamanhos de campo disponíveis no Mamógrafo Senographe DMR utilizado, e distancias focofilme iguais a $56 \mathrm{~cm}, 61 \mathrm{~cm}$ e $66 \mathrm{~cm}$. Os resultados obtidos foram comparados com publicações existentes, as quais apresentam resultados obtidos através de Simulação Monte Carlo, câmaras de ionização, e dosímetros TLD-100.

Os resultados obtidos neste trabalho permitem estabelecer e discutir as dependências das grandezas dosimétricas estudadas com a Camada Semi-Redutora, tensão do tubo, combinação ânodo-filtro, tamanho de campo, distância foco-filme e espessura da mama.

Palavras-chaves:Dose de entrada na pele; Dose em profundidade; Fator de retroespalhamento. 


\begin{abstract}
CAMARGO MENDOZA, R.E. Determination of dosimetric quantities of interest in Mammography using thermoluminescent detectors. [Dissertation]. Ribeirão Preto: Faculdade de Filosofia Ciências e Letras de Ribeirão Preto, Universidade de São Paulo; 2010. 66 p.

National and international health organizations such as the Brazilian Ministry of Health, through its Secretary of Health Surveillance establishes in the publication $N^{\circ} 453 / 98$ that in all mammographic equipments must be evaluated the entrance-skin dose through the readings of an ionization chamber-electrometer system corrected by the backscatter factor, among others factors. Nevertheless, there is no explicit mention for useful values of backscatter factor in this document; the main aim of this work is the experimental determination of backscatter factor through the use of TLD-100 dosimeters. In this study, the geometric and spectral dependencies of the backscatter factor, entrance-skin dose and the in-depth dose were evaluated, corresponding to the most radiographic techniques employed in conventional mammographic procedures, i.e., beam qualities in the range of $0.35 \mathrm{mmAl}$ to $0.43 \mathrm{mmAl}$, tube voltages from $25 \mathrm{kV}$ to $32 \mathrm{kV}$, focus-film distances from $56 \mathrm{~cm}$ to $66 \mathrm{~cm}$, and three field sizes were evaluated. Our results were compared with those previously published obtained through Monte Carlo simulation, ionization chambers and TLD dosimeters.

The results obtained in this work allow studying the dependency of the mentioned dosimetric quantities with the half-value layer, tube voltage, anode-filter combination, field size, focusfilm distance and breasting thickness.
\end{abstract}

Keywords: entrance-skin dose, in-depth dose, backscatter factor, TLD dosimeter 


\section{CAPÍTULO 1}

\section{INTRODUÇÃO}

A mamografia constitui ainda hoje o exame mais eficaz para detectar anomalias nas mamas, sobretudo o câncer no seu estágio inicial, permitindo que o tratamento seja executado com maior sucesso e com menos seqüelas.

Atualmente, nos aparelhos radiográficos, e em particular nos mamógrafos, os avanços tecnológicos têm buscado cada vez mais, produzir uma imagem com alto contraste, alta resolução espacial, e com o mínimo de dose de radiação possível (HAUS, 2002).

Os mamógrafos se diferenciam dos aparelhos de raios-X convencionais porque apresentam um espectro de menor energia efetiva que os utilizados em radiografia convencional, tornando possível a diferenciação dos tecidos mamários adiposos e fibroglandulares, ambos de densidades muito próximas. Para tanto, os mamógrafos atuais utilizam ânodos de molibdênio (Mo) ou de molibdênio e de ródio (Rh), como nos modelos da General Electric, em vez de ânodos de tungstênio (W), utilizados em exames convencionais de raios-X (HAUSS, 2002), entretanto a mamografia digital tem combinado este último material com baixos valores de tensões do tubo para obter imagens com melhor qualidade.

Embora os benefícios dos exames mamográficos sejam maiores que seus eventuais efeitos prejudiciais, deve-se atentar para a sensibilidade dos tecidos mamários (fibroglandulares) à radiação, existindo o risco de indução de câncer (LESTER,1997).

Assim sendo, a dose administrada nos exames mamográficos, principal fator para quantificar este efeito indesejável, deve ser quantificada e monitorada, além de minimizada (IPSM, 1994).

A determinação acurada, da dose de radiação na região de interesse, não pode ser realizada de forma direta, sendo geralmente obtida através da leitura de um dosímetro, que é convertida em dose após ser corrigida por vários fatores, tais como o fator de calibração, dependência energética, fator de retroespalhamento, etc. (HENDRICK, 1990).

No Brasil, por exemplo, deve-se determinar a dose na superfície da mama ou Dose de Entrada na Pele $(D E P)$, utilizando um sistema câmara de ionização-eletrômetro e simuladores mamários, de acordo com metodologia expressa na Guia: "Radiodiagnóstico Médico- 
Segurança e desempenho de equipamentos", aprovada e estabelecida pela resolução RE Nº1016 do Ministério da Saúde (MINISTERIO DA SAÚDE - Secretaria de Vigilância Sanitária, 2006).

Segundo essa metodologia, a $D E P$ é obtida através da leitura de uma câmara de ionização (kerma no ar), corrigida pelo fator de temperatura e pressão $\left(\mathrm{k}_{\mathrm{PT}}\right)$, fator de calibração $\left(f_{c}\right)$, e o fator de retroespalhamento (Back-Scatter Factor ou BSF).

A utilização do fator de retroespalhamento se justifica, porque a dose na superfície da mama (durante o exame) tem contribuição, além do feixe primário incidente, da radiação retroespalhada pela mama diferentemente da medida realizada no ar (sem simulador) com a câmara de ionização. (MINISTERIO DA SAÚDE - Secretaria de Vigilância Sanitária, 2006).

No ano de 1941, Mayneord e Lamerton, publicaram a primeira tabela dos fatores de retroespalhamento, tabulados apartir de resultados publicados por outros autores durante a década de 1930. Estes trabalhos foram realizados para energias na faixa de 0,5 $\mathrm{mm}$ até 17 $m m$ de $\mathrm{Cu}$ de camada semiredutora (CSR ou $H V L$ ), bem acima das energias aplicadas em mamografia. (KLEVENHAGEN, 1991)

O British Journal of Radiology (BJR) publicou, nos seus suplementos 5 (1953), 11 (1972), e 17 (1983), valores de fatores de retroespalhamento para raios-X de energias baixas, inclusive na faixa de energia usada em mamografía. Com o crescente interesse científico de melhorar a acuracia dosimétrica em radiologia diagnóstica, estes fatores foram melhor estudados por outros investigadores, por exemplo as publicações de Dubuque et al (1977), Klevenhagen (1982), Stanton et al (1982), e Harrison (1982). Os valores dos fatores de BSF publicados por estes autores, na faixa acima de $1 \mathrm{~mm}$ de Al da CSR, tem muita concordância com os valores do British Journal of Radiology. Entretanto, na faixa correspondente à CSR menores de $1 \mathrm{~mm}$ de Al o trabalho de Dubuque et al. (1977) apresenta valores de fatores de retroespalhamento significativamente diferentes dos valores do $B J R$.

Em 1984 Grosswendt calculou, através de simulação Monte Carlo, valores de BSF para raios-X polienergéticos gerados entre $10 \mathrm{kV}$ e $100 \mathrm{kV}$, sendo seus valores consideravelmente diferentes daqueles publicados pelo $B J R$, especialmente na faixa de $0,1 \mathrm{~mm}$ até $1,0 \mathrm{~mm}$ de $\mathrm{Al}$ de CSR.

Klevenhagen em 1989 apresentou valores de BSF obtidos com uma câmara de ionização especialmente desenhada para esse fim, numa faixa de $0,1 \mathrm{~mm}$ até $4 \mathrm{~mm}$ de $\mathrm{Al}$ de 
CSR (16kV até $140 \mathrm{kV})$, os quais têm semelhença com os resultados obtidos por Grosswendt, 1984.

Em 1996, a European Comission, publicou o Protocolo Europeu sobre Dosimetria em Mamografia, onde é apresentada uma tabela de valores de fatores de retroespalhamento em função da camada semiredutora (CSR). É importante mencionar que maioria dos trabalhos mencionados anteriormente foram realizados em laboratorios de calibração, ou desenvolvidos através de cálculos computacionais (simulação Monte Carlo), em condições geométricas e espectrais ligeiramente diferentes daquelas encontradas em exames mamográficos (GROSSSWENDT,1990; CHAN,1981).

Kramer e colaboradores, no ano 2000, utilizaram simulação Monte Carlo para calcular o $B S F$. Eles usaram como referência o modelo de exposição proposto pelo Protocolo Europeu sobre Dosimetria em Mamografia, além disso e diferentemente dos outros trabalhos, levaram em conta em seu estudo as condições de exposição de forma muito específica ao mostrar a dependencia do $B S F$ em função da CSR, tensão do tubo, combinação ânodo-filtro, espessura do simulador, set-up de irradiação empregado, e a distancia foco-superficie entre outros parâmetros importantes.

$\mathrm{Na}$ consideração do risco asociado à dose, tem sido assinalado que o tecido glandular da mama é mais vulnerável à carcinogênese por efeito da radiação, que a pele. A determinação acurada da Dose em Profundidade é importante para avaliar o risco de carcinogênesi em mamografia, permitindo garantir valores de dose que podem ser avaliados de forma reprodutivel, o qual é importante para selecionar uma técnica mamográfica adequada (STANTON, 1984).

A determinação experimental das grandezas dosimétricas, como o $B S F$, a $D E P$ e a Dose em Profundidade $\left(D_{P}\right)$, requerem a utilização de detetores que apresentam número atômico semelhante ao tecido humano e tamanho reduzido, de forma a atenuar o feixe primário e cumprir ao máximo a definição destas grandezas (ATTIX, 1986). A maioria das câmaras de ionização existentes, não permitem a determinação destas grandezas, por seu desenho (a maioria são protegidas contra retroespalhamento) e, principalmente por seu tamanho. Entretanto, os detetores termoluminescentes (por exemplo TLD-100) oferecem características de número atômico próximo ao dos tecidos e tamanho reduzido, características vantajosas para este tipo de medição. 
A maioria dos trabalhos publicados, relacionados com a medição das grandezas dosimétricas de interesse deste estudo, apresentam valores obtidos através da simulação Monte Carlo, e poucos foram desenvolvidos experimentalmente, devido entre outras razões ao insuficiente conhecimento da distribução energética da radiação espalhada quando determinadas experimentalmente (CARLSSON, 1993).

CARLSSON 1968, e STANTON 1981, entre outros, têm realizado a determinação experimental do $B S F$ utilizando TLD-100; HAMMERSTEIN no1979 DETERMINOU a dose em profundidade $\left(D_{p}\right)$ através do uso deste tipo de dosímetros TL. Uma comparação entre os resultados obtidos na determinação das grandezas, obtidos experimentalmente e por simulação, é apresentada neste trabalho.

Dada a importância da obtenção do $B S F$, da $D E P$ e da $D_{P}$, este trabalho tem como seu objetivo principal a determinação experimental destas grandezas, verificando suas principais dependências espectrais e geométricas paras as diversas condições clínicas de rotina, utilizando dosímetros termoluminescentes de LiF:Mg:Ti (TLD-100).

Nos próximos capítulos do presente trabalho se descreve o planejamento e desenvolvimento dele. Primeiramente, no próximo capítulo, são apresentados e descritos os materiais empregados para a obtenção das grandezas dosimétricas de interesse deste estudo, os equipamentos utilizados para irradiar os $T L D$, lê-los, e tratá-los termicamente.

Também é descrita a metodologia utilizada tanto na caracterização dos dosímetros como na determinação das grandezas dosimétricas, incluindo a apresentação dos arranjos experimentais utilizados para sua obtenção experimental.

Posteriormente, no capítulo de resultados e discussões são apresentados, analisados e comparados os resultados obtidos neste trabalho com os apresentados na literatura, através de tabelas e gráficos.

Finalmente, se apresentam as conclusões, entre as que se destacam: a adequação da utilização dos TLD-100 na determinação das grandezas estudadas; e as dependências, tanto geométricas como espectrais do $B S F$. 


\section{CAPÍTULO 2}

\section{MATERIAIS E MÉTODOS}

Os materiais, arranjos experimentais e os métodos utilizados na determinação das grandezas dosimétricas: Dose de entrada na pele $(D E P)$, Fator de Retroespalhamento $(B S F)$, e Dose em Profundidade $\left(D_{p}\right)$, são apresentadas neste capítulo.

\subsection{Dosímetros Termoluminescentes de Fluoreto de Lítio}

Neste trabalho foi utilizado como o instrumento fundamental de medição, o dosímetro termoluminescente (TLD) de Fluoreto de Lítio (LiF:MG:Ti), dopado com magnésio e titânio (LiF:MG:Ti) conhecido comercialmente como TLD-100.

O LiF é um material do grupo dos alógenos, com densidade de $2,6 \mathrm{~g} / \mathrm{cm}^{3}$ e número atômico efetivo igual a 8,2 (CAMERON et al., 1968; McKINLAY et al.,1981), próximo do número atômico efetivo do tecido humano, o qual varia entre 7,0 e 7,5, podendo ser considerado material "tecido equivalente" (CAMERON \& SKOFRONICK,1978), estas características fazem com que os TLD de LiF sejam muito usados em radiodiagnóstico.

O LiF não é solúvel em água e possui uma eficiência termoluminescente igual aos $0,039 \%$.

O $T L D-100$ possui $92,5 \%$ de ${ }^{7} \mathrm{Li}$ e $7,5 \%$ de ${ }^{6} \mathrm{Li}(\mathrm{CAMMERON}$ et al ,1968), é obtido através da fusão homogênea do fluoreto de lítio, fluoreto de magnésio, e titânio, dando como resultado uma substância contendo no máximo 180 ppm de Magnésio (Mg) e 10 ppm de Titânio (Ti) como impurezas ativadoras (CAMMERON \& SKROFONICK, 1978).

O TLD-100 utilizado neste trabalho é um cristal que tem dimensões de $0,9 \mathrm{~mm} \mathrm{x}$ $3,1 \mathrm{~mm} \times 3,1 \mathrm{~mm}$, e uma massa média de $23,6 \mathrm{mg}$. A figura 2.1 apresenta uma imagem do dosímetro empregado neste trabalho. 


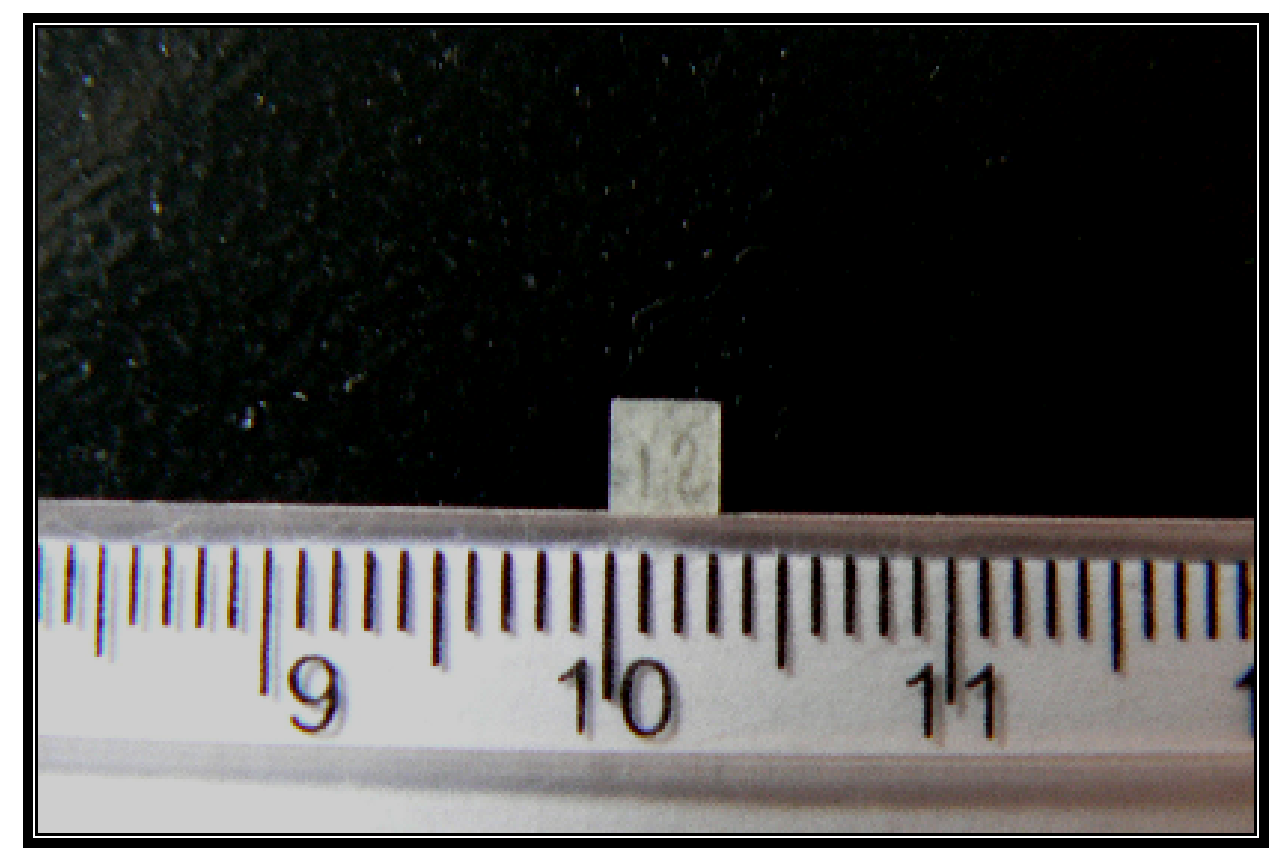

Figura 2.1- Imagem de um dosímetro $T L D-100$ de LiF

Entre as vantagens, apresentadas por CAMMERON (1968), e ATTIX (1986), quanto à utilização dos dosímetros TLD-100 destacam-se:

1. Não precisam de uma embalagem especial e são portáteis.

2. O número atômico da maioria dos detetores é similar ao tecido equivalente.

3. A persistência do sinal termoluminescente por longos períodos permite a medição, depois da irradiação no momento conveniente.

4. São reutilizáveis e, portanto econômicos.

5. Detetam nêutrons, raios- $\mathrm{X}$, raios gama, raios betas e elétrons.

6. A eficiência termoluminescente, o quociente entre a energia media emitida como luz termoluminescente e a energia média fornecida ao material termoluminescente (TL) pelo campo de radiação, é independente da taxa de dose.

7. Pode-se obter precisões melhores que $3 \%$ (eventualmente 1 ou $2 \%$ em sistemas otimizados) para dose no intervalo de $0,1 m G y$ a $10 G y$ (suficiente na maioria das aplicações de radiodiagnóstico, radioterapia, radiobiológicas e de dosimetria pessoal).

8. O sinal termoluminescente é relativamente simples de se avaliar, e pode-se automatizar sua avaliação. 
9. Sua leitura é rápida $(<30 \mathrm{~s})$.

Entre as desvantagens que apresentam os dosímetros $T L D$-100 podem-se destacar:

1. Não são dosímetros absolutos, precisam de uma calibração com um campo de referencia padrão, o que incrementa o erro na medida do sinal.

2. Efeitos de superfície podem produzir mudanças na transmissão luminosa devido aos riscos e à absorção gasosa que pode também alterar a eficiência intrínseca, ou produzir sinais não induzidos pela radiação.

3. As não homogeneidades do grupo fazem o que sua eficiência TL, bem como sua resposta dependa muito da distribuição espacial da concentração de armadilhas. Como os defeitos são dependentes das impurezas num nível de partes por milhão e de sua história radiante e térmica, é muito difícil fixar as propriedades de um material TL. Para obter uma ótima precisão devem-se realizar calibrações individuais para cada dosímetro.

4. Perda da informação: o método de obtenção da informação é destrutivo, e se por algum motivo (por exemplo, o mau funcionamento do tubo fotomultiplicador) a leitura não é recebida pelo sistema, e a informação contida no dosímetro é perdida.

5. Os dosímetros irradiados não mantêm permanentemente toda a informação armazenada neles, dando como resultado uma perda gradual do sinal latente termoluminescente, efeito chamado de $F A D I N G$, o qual deve ser corrigido avaliando-se a perda de informação em função do tempo, ou em seu defeito, fazendo-se tratamentos térmicos prévios à leitura.

\subsection{Tratamento Térmico}

O tratamento térmico tem por finalidade reconstituir ao dosímetro as condições existentes antes da exposição à radiação ionizante, ou seja, remover o sinal residual. $\mathrm{O}$ tratamento térmico empregado neste trabalho, foi o recomendado pelo fabricante de dosímetros Thermal Electron-Eberline, e pela Netherlands Commission on Radiation Dosimetry (NCRD, 1993). 
O ciclo do tratamento térmico dos TLDs consistiu das seguintes etapas:

- Aquecimento pré-irradiação;

- Irradiação;

- Aquecimento pós-irradiação;

- Leitura da energia armazenada, que é proporcional à carga elétrica, medida em Coulomb.

Primeiramente é realizado o tratamento térmico pré-irradação à alta temperatura, que tem por objetivo preparar o dosímetro para uso, apagando todas as informações (luminescência) existentes no TLD devido às irradiações passadas.

Nesta fase do tratamento térmico as pastilhas são submetidas a uma temperatura de $400{ }^{\circ} \mathrm{C}$ por uma hora no forno, com o objetivo de eliminar sinais residuais de termoluminescencia do dosimetro e restaurar sua sensibilidade, fase também conhecido como de regeneração (VIEGAS, 2003).

Depois é feito o tratamento térmico pré-irradação, à baixa temperatura, em uma estufa onde os dosímetros são aquecidos a $100^{\circ} \mathrm{C}$ por duas horas, tendo como objetivo reduzir o desvanecimento.

Após a irradiação dos dosímetros e previamente à leitura, foi levado em conta que os materiais termoluminescentes apresentam curvas de emissão com vários picos. Alguns desses picos estão localizados em baixas temperaturas e sujeitos a um decaimento térmico considerável à temperatura ambiente. Desta forma, antes de se efetuar a leitura do dosímetro termoluminescente, após sua irradiação, é conveniente fazer o tratamento pré-leitura, aquecendo os dosímetros a uma temperatura abaixo da temperatura de avaliação (SQUIRE, 2008). Nesta etapa os dosímetros foram aquecidos na estufa numa temperatura de $100^{\circ} \mathrm{C}$ por 15 minutos, com a finalidade de eliminar estes picos instáveis (NOGUEIRA, 1997).

A tabela 2.1 sumariza as etapas do tratamento térmico utilizado. 
Tabela 2.1- Temperaturas e tempos das etapas do Tratamento Térmico

\begin{tabular}{cc}
\hline Tratamento Térmico & Temperatura e tempo de aquecimento \\
\hline Pre-irradiação a Alta Temperatura & $400{ }^{\circ} \mathrm{C}$ por 60 minutos \\
Pre-irradiação a Baixa Temperatura & $100{ }^{\circ} \mathrm{C}$ por 120 minutos \\
\hline
\end{tabular}

O forno e a estufa têm um papel fundamental no desenvolvimento do tratamento térmico, por tanto na seguinte secção são detalhadas as características destes equipamentos.

\subsection{Forno e Estufa}

Para a etapa de aquecimento pré-irradiação foram utilizados o forno e a estufa empregados no tratamento dos TLD-100 do Centro de Instrumentação, Dosimetria e Radioproteção (CIDRA), da Faculdade de Filosofia, Ciências e Letras de Ribeirão Preto Universidade de São Paulo.

Foi utilizado um forno da BRAVAC ${ }^{\circledR}$, apresentado na figura 2.2, com controlador analógico de temperatura, controlador de temperatura com escala até $997{ }^{\circ} C$, chave de controle de potência com 4 posições (desligado, mínimo, médio e máximo), alarme sonoro e visual de fim de processo, e de dimensões úteis: $\mathrm{A}=95 \mathrm{~mm}, \mathrm{~L}=120 \mathrm{~mm}, \mathrm{P}=150 \mathrm{~mm}$. 


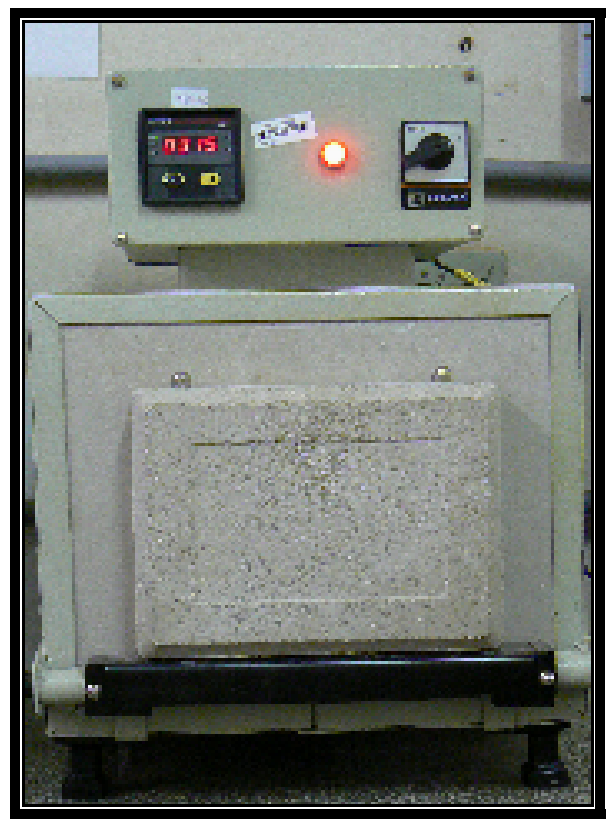

Figura 2.2- Forno empregado para fazer o tratamento térmico pré-irradiação

A estufa empregada é de convecção forçada de ar para esterilização e secagem, da OLIDEF $\mathrm{CZ}^{\circledR}$, apresentada na figura 2.3 , com temperaturas de $40^{\circ} \mathrm{C}$ até $300{ }^{\circ} C$, e uma capacidade de 34 litros.

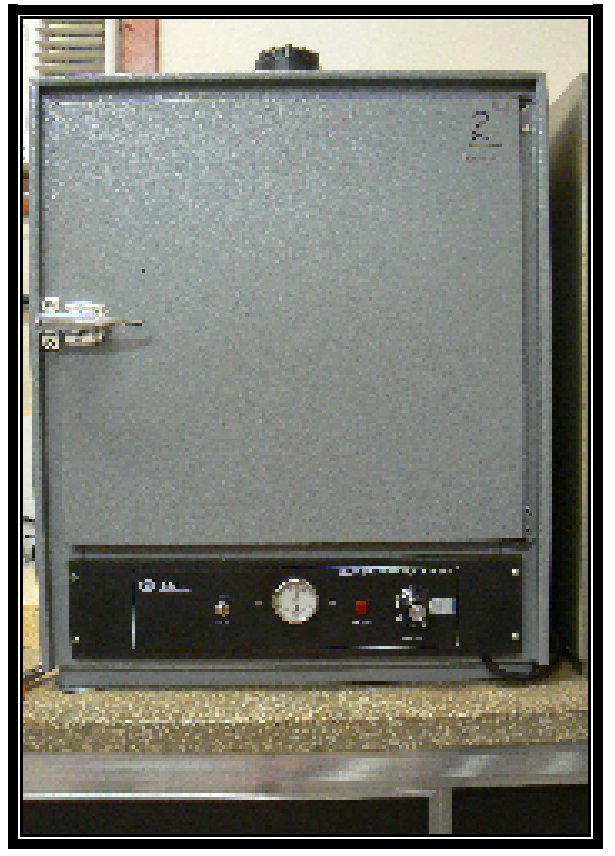

Figura 2.3- Estufa utilizada para o tratamento térmico dos TLDs. 
Uma vez feito o tratamento térmico, os dosímetros podem ser irradiados; neste trabalho foram utilizadas duas fontes de radiação as quais são detalhadas na próxima seção.

\subsection{Fontes de radiação utilizadas}

\subsubsection{Fonte de ${ }^{137} \mathrm{Cs}$}

Para efetuar a caracterização dos dosímetros foi utilizada uma fonte de ${ }^{137} \mathrm{Cs}$, a qual é uma fonte de raios- $\gamma$ com uma meia-vida de 30 anos (11 018,3 \pm 9,5) dias, com taxa de dose, reportada pelo CIDRA igual a $0,082 \mathrm{mGy} / \mathrm{min}$. Sendo que a ultima calibração da fonte foi feita ao inicio do 2009, e considerando sua meia-vida, não foi feita a correção para o decaimento. Os TLDs foram posicionados numa distância de $18 \mathrm{~cm}$ da fonte.

O valor desta taxa de dose é aproximadamente igual para qualquer ponto localizado na região compreendida dentro do suporte cilíndrico apresentado na figura 2.4 .

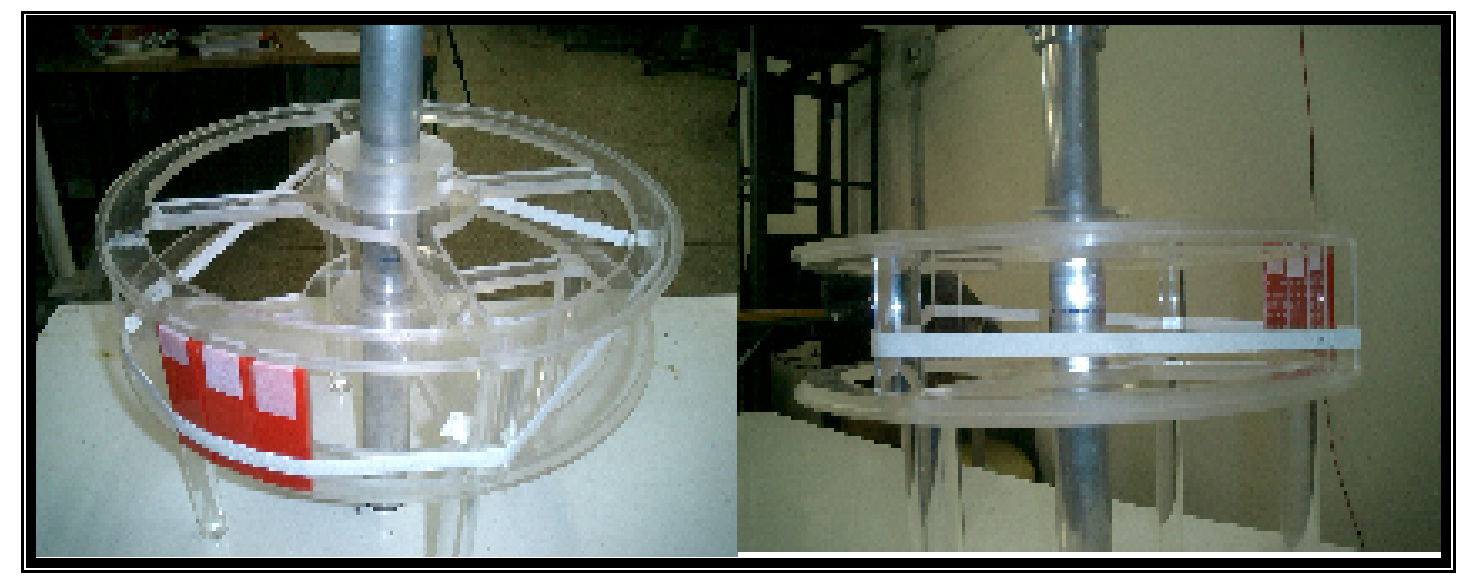

Figura 2.4- Imagem do suporte para o posicionamento da fonte de ${ }^{137} \mathrm{Cs}$ e do suportes contendo os TLDs. 


\subsubsection{Mamógrafo Senographe DMR}

Para avaliar as grandezas dosimetricas de interesse neste trabalho, utilizou-se um Mamógrafo Senographe DMR (GE $\left.{ }^{\circledR}\right)$ do Hospital das Clínicas-USP-RP com ânodos de Mo e $\mathrm{Rh}$, e filtros de Mo, Rh e Al, o qual permite diferentes combinações ânodo-filtro.

O sistema Senographe DMR (figura 2.5), é projetado para realizar exames de alta qualidade de diagnóstico mamográfico, localizações de nódulos, e biopsias.

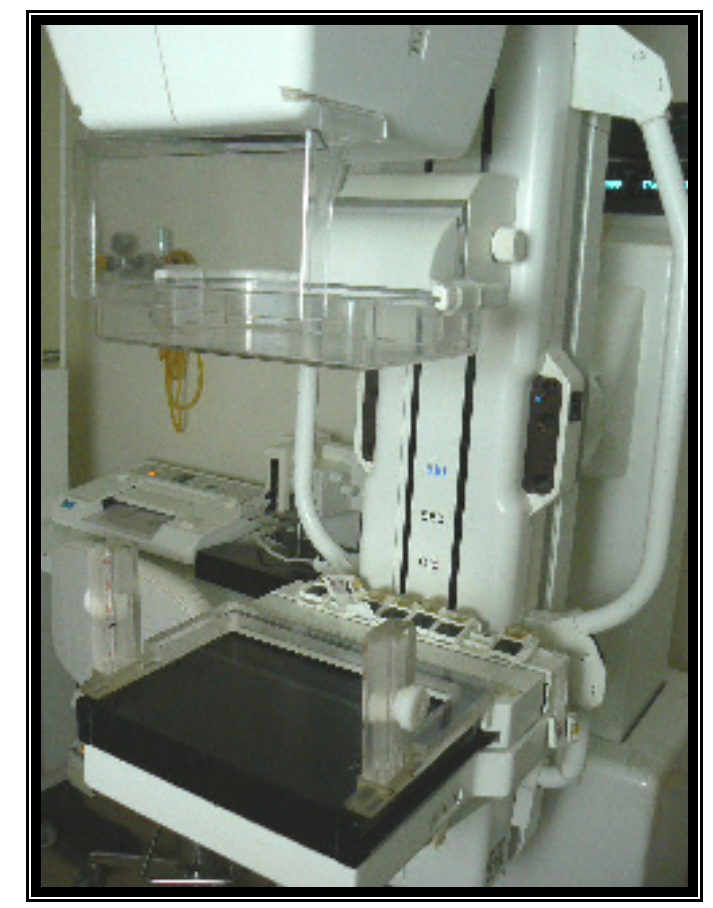

Figura 2.5- Mamógrafo Senographe DMR (GE®) do Hospital das Clínicas-USP-RP

Neste trabalho, os valores da tensão aplicados ao tubo foram de $25 \mathrm{kV}, 28 \mathrm{kV}, 30 \mathrm{kV}$ e $32 \mathrm{kV}$, sendo esses valores de tensão de uso frequente nos exames mamográficos de rotina. Antes de efetuar as irradiações dos dosímetros, foi feita a verificação da exatidão e reprodutibilidade da tensão do tubo, e determinação da camada semiredutoras para as combinações ânodo-filtro usadas, seguindo o procedimento estabelecido na guia implementada pela ANVISA (MINISTÉRIO DA SAÚDE, 2005). 
As metodologias utilizadas na avaliação da exatidão e reprodutibilidade da tensão do tubo, e para a obtenção da CSR foram as estabelecidas na Guia: "Radiodiagnóstico médicoSeguranza e desempenho de equipamentos" (ANVISA, 2006).

Para avaliar a exatidão e reprodutibilidade da tensão do tubo foi utilizado o sistema Nero ${ }^{\circledR}$ Victoreen. Para a determinação da camada semiredutora. utilizou-se equipamentos calibrados, como o sistema Nero ${ }^{\circledR}$ Victoreen, filtros de alumínio com 99\% de pureza, e o conjunto câmara-eletrômetro. A câmara de ionização utilizada foi uma câmara para mamografia 10X5-6M e eletrômetro 9015 RM-S, ambos da Radcal Corporation (figura 2.6), devidamente calibrados no Instituto de Pesquisas Energéticas e Nucleares (IPEN), para a faixa energética de mamografia.

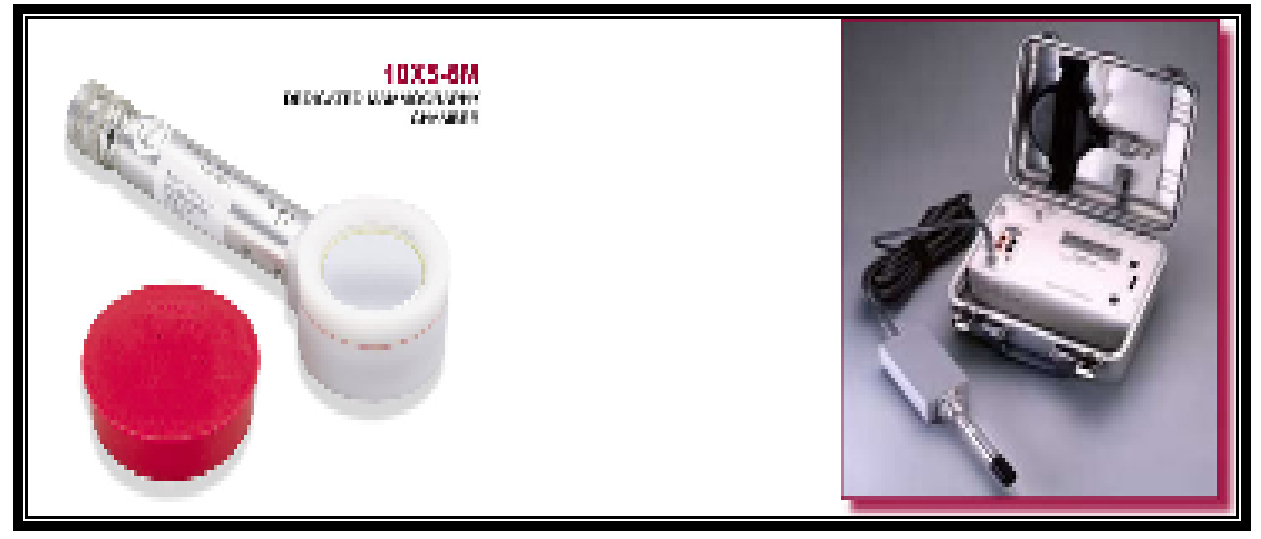

(a)

(b)

Figura 2.6- a- Câmara de Ionização para mamografia 10X5-6M b- Eletrômetro 9015 RM-S

Os testes efetuados verificaram que o mamógrafo utilizado possui valores de tensão, e CSR dentro dos limites de aceitação estabelecidos na Guia: "Radiodiagnóstico médicoSeguranza e desempenho de equipamentos" (MINISTERIO DA SAÚDE, 2005).

Após a irradiação dos dosímetros nas fontes descritas, a leitura do sinal termoluminescente de cada dosímetro foi feita usando o sistema leitor termoluminescente, o qual é apresentado na próxima seção. 


\subsection{Sistema Leitor}

Para obter o sinal termoluminescente dos dosímetros, foi utilizado um sistema leitor manual de termoluminescência TL Harshaw Chemical Co., modelo 2000 C, com taxa de aquecimento de $10{ }^{\circ} \mathrm{C} / \mathrm{s}$, localizado no CIDRA.

Os equipamentos leitores de sinal dos detectores TL, sejam manuais ou automáticos, possuem três partes básicas apresentadas na figura 2.7 (SQUIRE, 2008).

- Sistema de aquecimento, que consiste em fornecer energia térmica ao detetor TL para produzir a recombinação do elétron na camada de valência emitindo luz visível; na leitora utilizada, o processo de aquecimento é feito através de uma resistência elétrica.

É importante mencionar que o sistema é vedado mecanicamente para impedir entrada da luz no momento da leitura. Além disso, permite a entrada de nitrogênio para produzir uma atmosfera inerte onde o detetor é aquecido na ausência de oxigênio, reduzindo assim sinais espúrios não induzidos pela radiação. (NARIYAMA,1993)

- Sistema de deteção da luz para captação do sinal TL emitido pelo detetor. Este sistema é constituído por lentes que direcionam o feixe de luz para tubos fotomultiplicadores, gerando o sinal elétrico com intensidade proporcional à emissão de luz.

- Sistema eletrônico, que consiste na amplificação e coleta do sinal elétrico obtendo o resultado da leitura em carga elétrica.

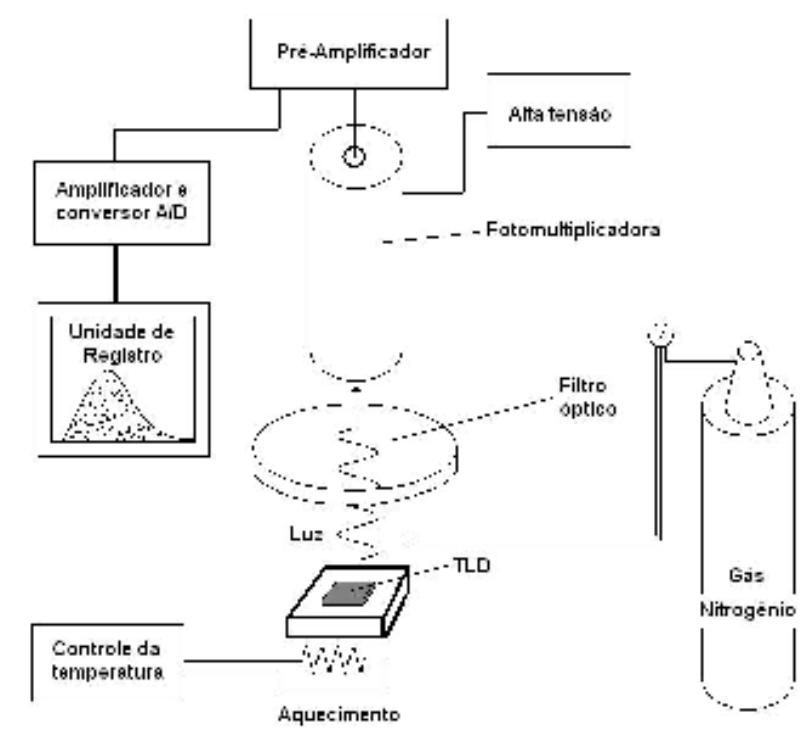

Figura 2.7- Partes básicas do Sistema Leitor de Termoluminescência 
Na figura 2.8-a pode-se observar o módulo A, o qual possui o sistema de aquecimento mencionado, e que consiste em uma prancheta metálica para acomodação do TLD, que funciona como uma resistência elétrica, aquecendo o dosímetro. Além da prancheta, o módulo A possui um tubo fotomultiplicador o qual converte a luz em corrente elétrica e a amplifica. A corrente amplificada é enviada para o módulo B (figura 2.7b), o quem a integra e apresenta o valor medido no visor.

A curva de emissão TL é obtida utilizando uma temperatura de aquecimento mínima de $50^{\circ} \mathrm{C}$ e máxima de $250^{\circ} \mathrm{C}$, uma vez que nesta faixa estão compreendidos os picos mais estáveis do sinal termoluminescente.

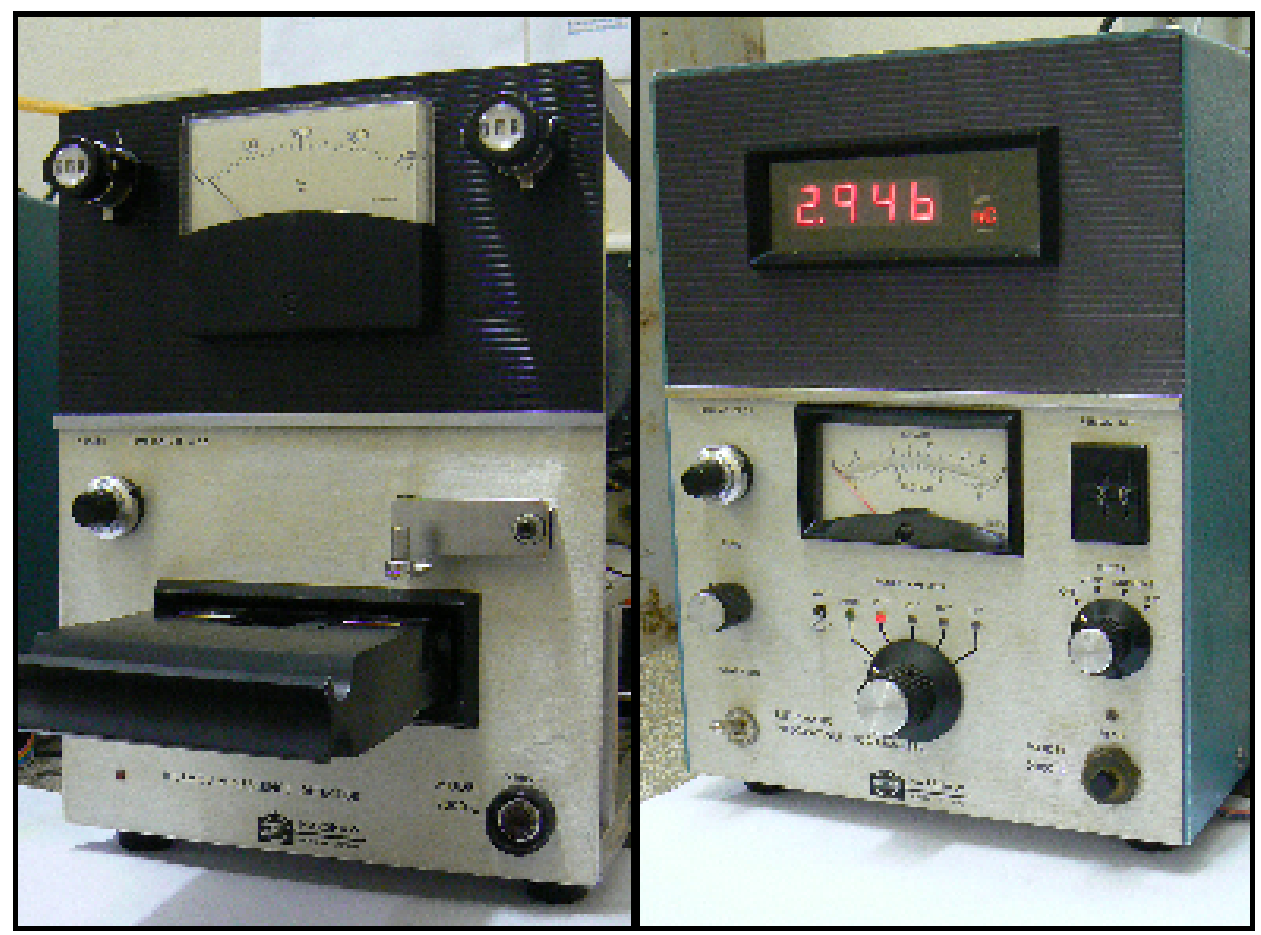

(a)

(b)

Figura 2.8- Sistema Leitor:

a. Modulo A contendo a prancheta e o tubo fotomultiplicador.

b. Modulo B integrador do sinal TL contendo o "display".

Ao posicionar os dosímetros na prancheta da leitora utilizada, teve-se o cuidado de manter sempre o mesmo posicionamento geométrico visando diminuir qualquer incerteza 
associada ao posicionamento dos dosímetros durante a leitura. (OLAYA, 2006). O valor da leitura, fornecida pelo sistema leitor TL, foi registrado e processado.

\subsection{Simuladores Mamários}

Para a determinação da $D E P$, do $B S F$, e da $D_{p}$, foram utilizados dois tipos de formatos de objetos simuladores mamários, construídos de um material homogêneo de polimetilmetacrilato (PMMA), com uma densidade de $1,19 \mathrm{~g} / \mathrm{cm}^{3}$ (TRAUB, 1997):

- Semicilíndricos (figura 2.9a), com raio de $10 \mathrm{~cm}$ e espessuras de $1 \mathrm{~cm}$ e $2 \mathrm{~cm}$. Estes simuladores imitam a forma de uma mama real comprimida, e foram utilizados na determinação da $D E P$, do $B S F$, e da $D_{p}$.

- Paralelepípedos (figura 2.9b), com dimensões de $30 \mathrm{~cm}$ x $30 \mathrm{~cm}$ x $2 \mathrm{~cm}$. Estes simuladores foram utilizados com a finalidade de avaliar a influência do tamanho da superfície irradiada na determinação do BSF. Eles são usados geralmente em laboratórios de calibração (DANCE, 2000; TRAUB et al., 1997; SCHAUERT et al., 2000).

O PMMA é recomendado pelo Institute of Physical Sciences in Medicine (IPSM) como um material simulador adequado para medidas de dose em mamografia. Existem cálculos que indicam que os simuladores de PMMA têm características para produzir retroespalhamento de fótons similarmente ao que apresentam os simuladores recomendados pela International Standarization Organization (ISO) e pela International Commission on Radiation Units and Measurements (ICRU). (TRAUB, 1997).

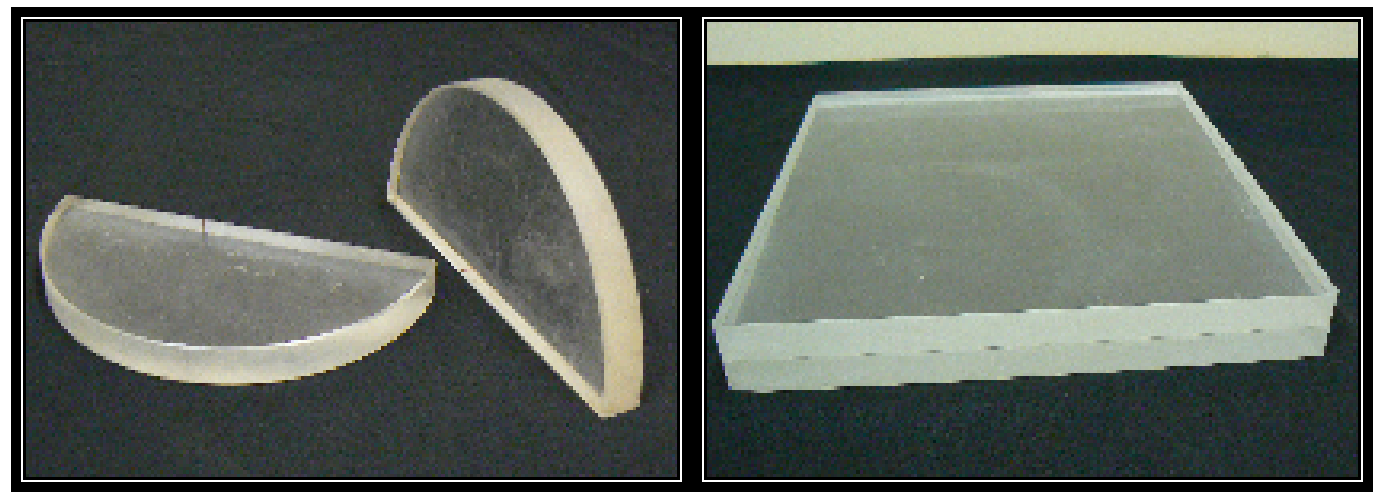

Figura 2.9- Simuladores mamários: a- Semicilíndrico de $10 \mathrm{~cm}$ de radio. b- Quadrados de $30 \mathrm{~cm} \times 30 \mathrm{~cm}$. 
Os simuladores utilizados neste trabalho são equivalentes ao tecido mamário de mulheres numa faixa etária compreendida dos 50 até os 64 anos, com uma percentagem de tecido glandular variável dependendo da espessura da mama (DANCE, 2000). Na tabela 2.2 são apresentados as porcentagem de tecido glandular para cada uma das espessuras da mama comprimidas, e a correspondente espessura equivalente para o simulador de PMMA (DANCE, 2000).

Tabela 2.2- Simuladores de mamas típicas em mulheres de 50 até 64 anos de idade usando blocos de PMMA. (DANCE, 2000)

\begin{tabular}{ccc}
\hline $\begin{array}{c}\text { Espessura } \\
\text { da mama } \\
(\mathrm{cm})\end{array}$ & $\begin{array}{c}\text { \% de tecido } \\
\text { glandular } \\
\text { Idades de 50 } \\
\text { até } 64 \text { anos }\end{array}$ & $\begin{array}{c}\text { Espessura } \\
\text { equivalente } \\
\text { de } \\
\text { PMMA }\end{array}$ \\
\hline 2,0 & 100 & 1,9 \\
3,0 & 72 & 2,8 \\
4,0 & 50 & 3,6 \\
5,0 & 33 & 4,3 \\
6,0 & 21 & 5,0 \\
7,0 & 12 & 5,6 \\
8,0 & 7 & 7,0 \\
\hline
\end{tabular}

Segundo a tabela 2.2, com os valores das espessuras dos simuladores de PMMA empregados neste trabalho, são simuladas mamas com espessuras aproximadamente iguais aos $2,1 \mathrm{~cm} ; 4,6 \mathrm{~cm}$ e $7,1 \mathrm{~cm}$, espessuras as que aproximadamente possuem uma percentagem de glandularidade iguais aos 97\%; 40\%, e 11\% respectivamente (DANCE, 2000).

Nas seguintes seções descreve-se a metodologia empregada na caracterização e calibração dos dosímetros, assim como os arranjos experimentais utilizados na irradiação dos dosímetros com a finalidade de se determinar em a $D E P$, o $B S F$ e a $D_{p}$. 


\subsection{Caracterização e Calibração dos dosímetros $T L D-100$}

A interpretação da leitura de um dosímetro em termos de uma quantidade que se deseja medir (Dose, Exposição, Kerma, etc...) é o objetivo central da dosimetria. Para que essa interpretação seja correta, primeiramente é necessário conhecer as principais características do dosímetro que está sendo utilizado.

Neste trabalho a caracterização dos dosímetros termoluminescentes, consistiu em avaliar, dentre outros, os seguintes parâmetros: Homogeneidade de grupo (HG), reprodutibilidade, fator de calibração $\left(f_{c}\right)$, linearidade e dependência energética (CAMMERON, 1968).

Nas seguintes seções serão apresentadas as metodologias seguidas neste trabalho, a fim de avaliar cada um dos parâmetros anteriormente mencionados.

\subsubsection{Homogeneidade de Grupo}

A homogeneidade de grupo, do lote de detectores termoluminescentes, é um parâmetro que serve para avaliar as flutuações nas respostas individuais dos dosímetros quando estes são irradiados sob as mesmas condições, recebendo uma determinada dose.

O critério da International Electrotechnical Commission (IEC) estabelece que o valor da leitura de qualquer dosímetro do conjunto, não deve ser diferente por mais $\operatorname{dos} 30 \%$ da leitura de outro dosímetro do mesmo conjunto (IEC 1066, 1991).

Para avaliar a HG a norma 1066 da $I E C$ estabelece a seguinte relação:

$$
\mathrm{HG}=\frac{\left(L_{\max }-L_{\min }\right)}{L_{\min }} \leq 30 \%
$$

$L_{\max }$ representa o valor da máxima leitura obtida.

$L_{\min }$ representa o valor da mínima leitura obtida.

Para obter os valores de máxima e mínima leitura, os dosímetros foram irradiados utilizando a fonte de ${ }^{137} \mathrm{Cs}$, e depois foi feita a leitura de cada TLD. 
A irradiação dos dosímetros foi realizada, neste teste, durante 61 minutos o que representou um valor de Dose absorvida $(D)$ de 5,0 $m G y$, o qual é um valor de dose característico em mamografia (ANVISA, 2005), visto que a taxa de dose para a fonte utilizada tem um valor de $0,082 \mathrm{mGy} / \mathrm{min}$.

\subsubsection{Reprodutibilidade}

A reprodutibilidade do detector representa a capacidade dos dosímetros de se manter estáveis nas suas respostas individuais durante utilizações sucessivas (SQUAIR, 2008).

O critério de avaliação da norma IEC 1066, estabelece que o coeficiente de variação (CV), não deve ser maior que 7,5\% para cada dosímetro individualmente:

$$
\mathrm{CV}=\left(\frac{S_{i}+I_{i}}{L_{i}}\right) \leq 7,5 \%
$$

$S_{i}$, representa o desvio padrão das leituras.

$L_{\mathrm{i}}$ representa o valor meio de cada leitura.

$I_{\mathrm{i}}$, representa a largura meia do intervalo de confiança de $95 \%$ para o $S_{i}$,

para cada dosímetro, determinado pela equação:

$$
I_{S}\left(n_{S}\right)=t_{n S} S \sqrt{\frac{0,5}{\left(n_{S}-1\right)}}
$$

$n_{S}$, é o número de medidas realizadas.

$S i$, é o desvio padrão das leituras de cada detector TL.

$t_{n S}$, é o valor adotado estatisticamente da tabela $t$-Student para o número de medidas realizadas (IEC 1066, 1991)

Para se obter o valor meio de cada leitura, o grupo inicial de dosímetros foi irradiado cinco vezes utilizando a fonte de ${ }^{137} \mathrm{Cs}$. 


\subsubsection{Determinação do Fator de Calibração}

A calibração dos dosímetros é realizada através da determinação do fator de calibração $\left(f_{c}\right)$ de cada $T L D$. O fator de calibração é um fator de conversão da carga gerada pela emissão da luz proveniente do cristal termoluminescente, durante sua leitura, em valores correspondentes a grandeza de interesse. (SQUIRE, 2005).

A sensibilidade termoluminescente é definida como a quantidade de luz emitida pelo $T L D$, representada pela leitura obtida $\left(L_{i}\right)$ por unidade da grandeza dosimetrica ministrada durante a irradiação, ou seja, o sinal TL por Kerma ou pela dose absorvida.

A sensibilidade pode ser expressa como (CAMERON, 1968):

$$
S_{T L}=\frac{L_{i}}{D}
$$

O $f_{c}$ constitui o inverso da sensibilidade dos dosímetros (equação 2.5), seu valor foi determinado para cada dosímetro individualmente, através dos resultados obtidos na leitura da resposta termoluminescente e da determinação da Sensibilidade de cada TLD.

$$
f_{c}=\frac{1}{S_{T L}}
$$

\subsubsection{Linearidade}

A linearidade consiste em verificar a estabilidade do dosímetro em relação à variação da sua resposta com o valor das doses submetidas neste trabalho, o teste foi desenvolvido uma vez feita a seleção dos dosímetros.

Uma sensibilidade $S$ constante através de um amplo intervalo de dose proporciona uma resposta linear, para o dosímetro:

$$
D_{i}=S . L_{i}
$$

Segundo a norma IEC 1066, o critério de avaliação estabelecido para a linearidade é o seguinte: 


$$
0,90 \leq \frac{L_{i} \pm I_{i}}{D_{i}} \leq 1,10
$$

$L_{\mathrm{i}}$,é o valor meio das leituras para cada dosímetro.

$I_{\mathrm{i}}$, é o intervalo de confiança para cada irradiação.

$D_{\mathrm{i}}$, é o valor da dose subministrada.

Os dosímetros foram irradiados em grupos utilizando a fonte de césio para os tempos, medidos em minutos, iguais aos: 6, 12, 23, 46, 73, e 120. Fazendo uso da taxa de dose da fonte, igual a $0,082 \mathrm{mGy} / \mathrm{min}$, estes tempos correspondem aos valores de dose, medidos em $m G y$, iguais aos: 0,$492 ; 0,984 ; 1,886 ; 3,772 ; 5,986 ; \mathrm{e} 9,840$ respectivamente.

\subsubsection{Dependência Energética}

Avaliar a dependência energética dos dosímetros é importante para estimar adequadamente a acurácia obtida neste trabalho. A dependência energética na resposta de um dosímetro é uma das principais fontes de incerteza na determinação do kerma no ar de um feixe de raios-X para uma dada $k V p$ (COSTA, 2008).

A dependência energética dos dosímetros termoluminescentes é definida como uma medida da energia absorvida pelo material TL em comparação com a energia absorvida por um material de referência (normalmente o ar), quando submetido a condições idênticas de exposição aos fótons (ATTIX, 1986). O teste da dependência energética avalia a resposta do dosímetro em relação à dose, quando são irradiados com fótons de diferentes energias.

Essa variação, relativa à condição de calibração, pode ser avaliada experimentalmente através da leitura (L) por unidade da grandeza que supostamente se quer medir, por exemplo: Dose, Kerma, Exposição, etc., relacionada com a sensibilidade obtida no feixe de calibração, representado pelos termos presentes no lado esquerdo da equação 2.8 .

Pode ser obtida teoricamente através da razão entre os coeficientes médios de absorção de massa do dosímetro e do ar, assumindo as mesmas condições de irradiação e de equilíbrio de partículas carregadas (EPC), tabulados geralmente em radiodiagnóstico em função da CSR do feixe a que é submetido, representado no lado direito da equação 2.8. 


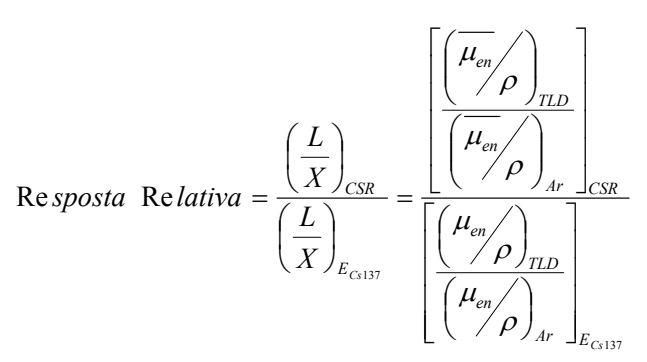

Onde $L$ representa a leitura de uma dada grandeza dosimétrica $X$, e $\frac{\mu_{e n}}{\rho}$ o coeficiente de absorção de energia em massa.

Neste trabalho a dependência energética foi avaliada em função da camada semiredutora para nove valores da CSR, correspondentes as diferentes combinações avaliadas de $k V p / m A s$ e ânodo/filtro.

Os dosímetros foram posicionados na mesma posição em que foi colocada a câmara de ionização (c.i), segundo a Guia "Radiodiagnóstico Médico: Segurança e desempenho de equipamentos da ANVISA, a 4,0 cm da parede torácica e a 4,5cm do porta-chassi. Os valores teóricos da resposta relativa, foram calculados utilizando os valores dos coeficientes de absorção de energia em massa do $\mathrm{LiF}$ e do ar, para as energias efetivas correspondente às CSR medidas obtidos em BERGER et al. (2007).

\subsection{Arranjos Experimentais}

Para obter as medições necessárias para calcular os valores de $D E P, B S F$, e da $D_{p}$, foram desenvolvidos e utilizados os arranjos experimentais os quais são apresentados nas próximas seções.

\subsubsection{Medida da Dose de Entrada na Pele}

"Os testes de controle da qualidade para equipamentos de raios-X convencionais $\mathrm{e}$ mamográficos devem incluir uma estimativa da dose de entrada na pele $(D E P)$ representativa dos exames praticados no serviço e os valores obtidos devem ser comparados com os níveis de referência de radiodiagnóstico apresentados no regulamento nacional. Deve ser enfatizado que os níveis de referência de radiodiagnóstico não são limites regulamentados, mas devem ser vistos como um dispositivo prático para promover um melhor controle da qualidade local. 
Uma estimativa acurada da dose de entrada na pele requer uma medição acurada do kerma no ar incidente no plano da entrada da pele e também da camada semi-redutora (CSR) do feixe. O kerma no ar incidente é convertido para dose de entrada na pele mediante aplicação de um fator de retro espalhamento apropriado" (COSTA, 2008).

O controle dos seguintes parâmetros é particularmente importante: tensão no tubo, reprodutibilidade e linearidade da taxa de kerma no ar com o produto corrente no tubo-tempo de exposição $(m A s)$. "As características desses parâmetros podem variar com o tempo; logo os testes precisam ser realizados em intervalos regulares" (COSTA, 2008).

No Brasil, deve-se determinar a dose na superfície da mama (ou dose de entrada na pele) utilizando, preferentemente, um sistema câmara de ionização-eletrômetro e simuladores mamários, segundo a metodologia expressa na Guia: "Radiodiagnóstico médico-seguranza e desempenho de equipamentos" (ANVISA, 2005).

Segundo essa metodologia, a $D E P$ é obtida através da leitura da câmara de ionização (kerma no ar) corrigida pelos fatores de: temperatura e pressão $\left(k_{P T}\right)$, correção $\left(f_{c}\right)$, e o fator de retro espalhamento $(B S F)$ de acordo com a seguinte equação:

$$
D E P=K_{a r} \cdot k_{P T} \cdot f_{c} \cdot B F S
$$

Neste trabalho, a $D E P$ foi determinada usando $T L D$, e os valores da $D E P$ obtidos através da câmara de ionização foram usados como referência para fazer as comparações.

As leituras obtidas nos dosímetros posicionados na superfície do simulador mamário para as diferentes espessuras do simulador, para cada valor de tensão do tubo e para cada combinação ânodo-filtro, conjuntamente com o resultado obtido para o teste da dependência energética dos dosímetros, foram usadas para efetuar o calculo da $D E P$.

A dose de entrada na pele sobre um simulador mamográfico, utilizando $T L D$ foi calculada através da seguinte expressão:

$$
D E P=L \cdot f_{c} \cdot f_{d}
$$


$L$ representa a leitura obtida na para o $T L D$ colocado na superfície do simulador (equivalente à superfície da pele).

$f_{\mathcal{c}}$, representa o fator de calibração do detector TL.

$f_{d}$, representa o fator de dependência energética.

Grupos de três $T L D s$ foram irradiados, de forma a reduzir as incertezas, os TLDs foram alinhados sobre o simulador mamário, a $4,5 \mathrm{~cm}$ da borda da porta-chassi, garantindo assim que ficassem na direção do eixo central do feixe de raios $\mathrm{x}$ do mamógrafo.

O arranjo experimental para a obtenção da $D E P$ foi montado conforme a figura 2.10 .

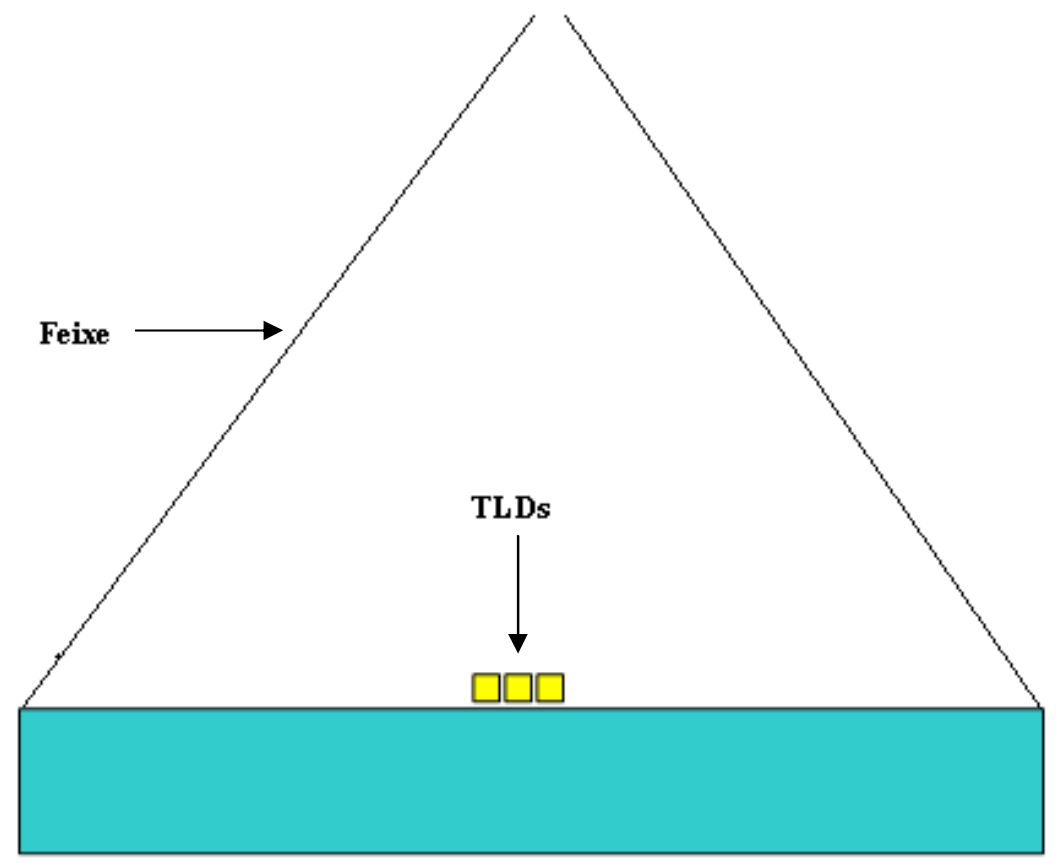

Figura 2.10- Arranjo experimental para a determinação da $D E P$ 


\subsubsection{Medida do Fator de Retroespalhamento}

Define-se o $B S F$ para um ponto de referência situado sobre o eixo do feixe de radiação, na superfície do tecido espalhador na intersecção tecido/ar, como a razão entre a dose neste ponto na presença do tecido espalhador $\left(D_{t e c}\right)$ e a dose na ausência deste $\left(D_{a r}\right)$; e para uma condição de equilibrio de partículas carregadas pode-se escrever como (JOHNS, 1983):

$$
B S F=\frac{D_{t e c}}{D_{a r}}=\frac{K_{c_{t e c}}}{K_{c_{a r}}}
$$

Grupos de três $T L D s$ foram irradiados, de forma a reduzir as incertezas, em duas condições experimentais: com e sem simulador. O arranjo experimental utilizado para a obtenção do $B S F$ é apresentado na Figura 2.11.

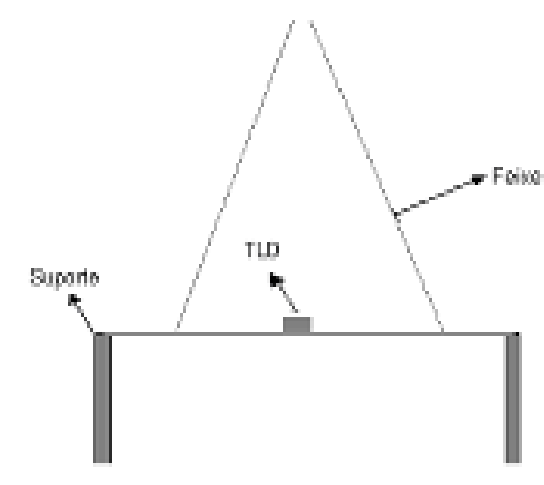

(a)

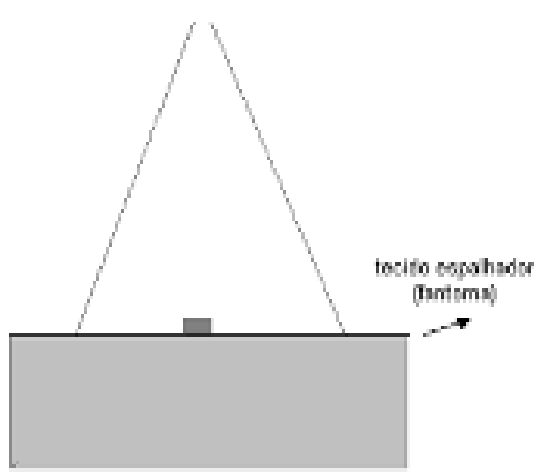

(b)

Figura 2.11: Esquema da medida da dose: a) sem o tecido espalhador b) com o tecido espalhador. 
Com o tecido espalhador: os TLDs foram alinhados sobre o simulador mamário, em relação ao eixo central do feixe de raios $\mathrm{x}$, e numa distância de $4,5 \mathrm{~cm}$ da borda da portachassi. A dose obtida nessa condição foi denominada como dose com tecido espalhador $\left(D_{\text {tec }}\right)$.

Sem tecido espalhador: foi construído um suporte que possui finos fios de nylon, sobre os quais foram posicionados os dosímetros. $\mathrm{O}$ uso do suporte tenta aproximar a condição do $T L D$ irradiado no ar. A figura 2.12 apresenta o suporte utilizado nesta condição.

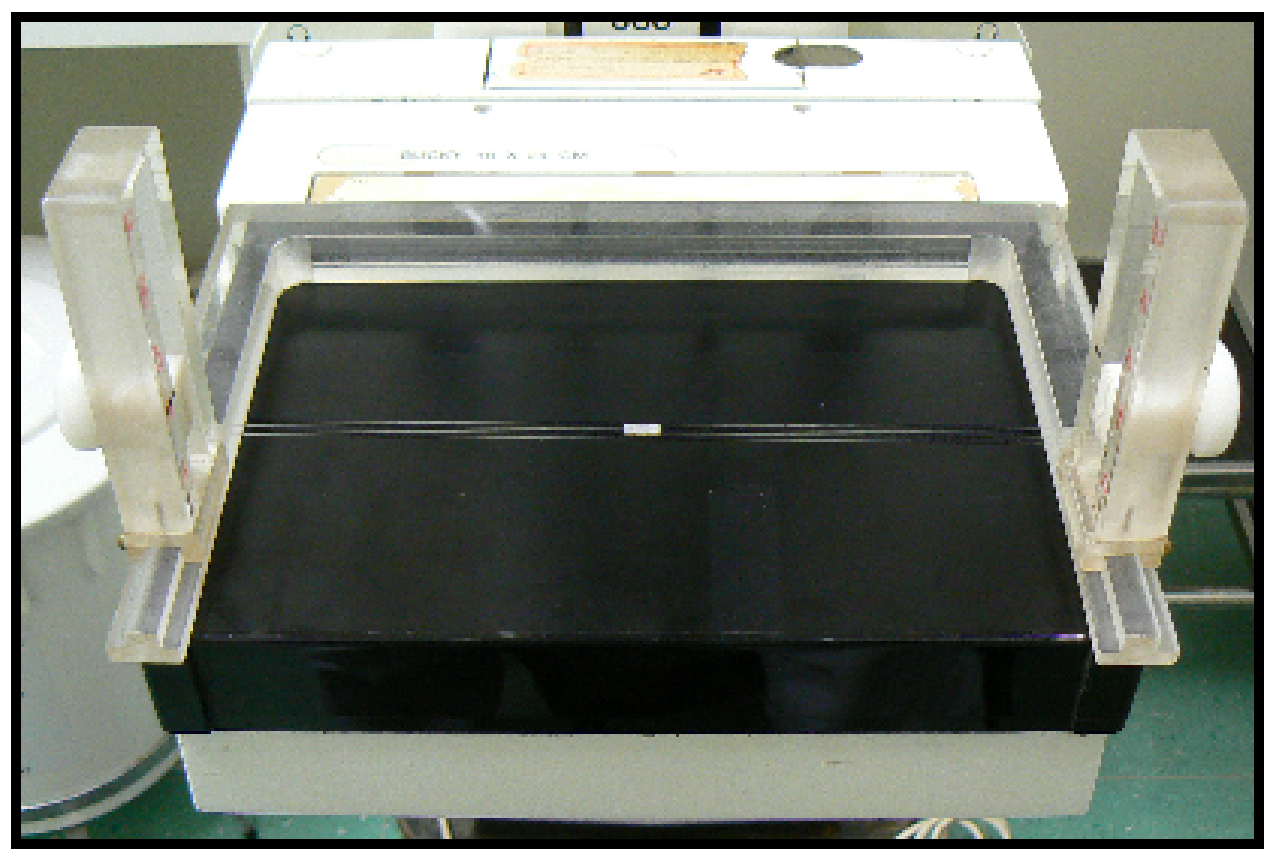

Figura 2.12- Arranjo experimental usado para irradiar os dosímetros na condição "sem tecido espalhador"

O suporte foi ajustado, para conseguir que os dosímetros sejam colocados numa posição similar à que tenham ao irradiá-los sobre o simulador mamário. 


\subsubsection{Medida da Dose em Profundidade}

O calculo da $D_{p}$ foi feita através da seguinte equação:

$$
D_{p}=L \cdot f_{c} \cdot f_{d}
$$

O arranjo experimental utilizado para medir a dose em profundidade, é apresentado na figura 2.13. Neste arranjo, são posicionados três dosímetros por vez, para cada profundidade, dentro de uma fenda aberta na superfície de um dos simuladores semicilindricos de PMMA. Para evitar à superposição dos dosímetros no momento da irradiação, e conseguir que cada conjunto de TLDs esteja aproximadamente na mesma posição que na irradiação precedente, as irradiações foram feitas separadamente para cada profundidade.

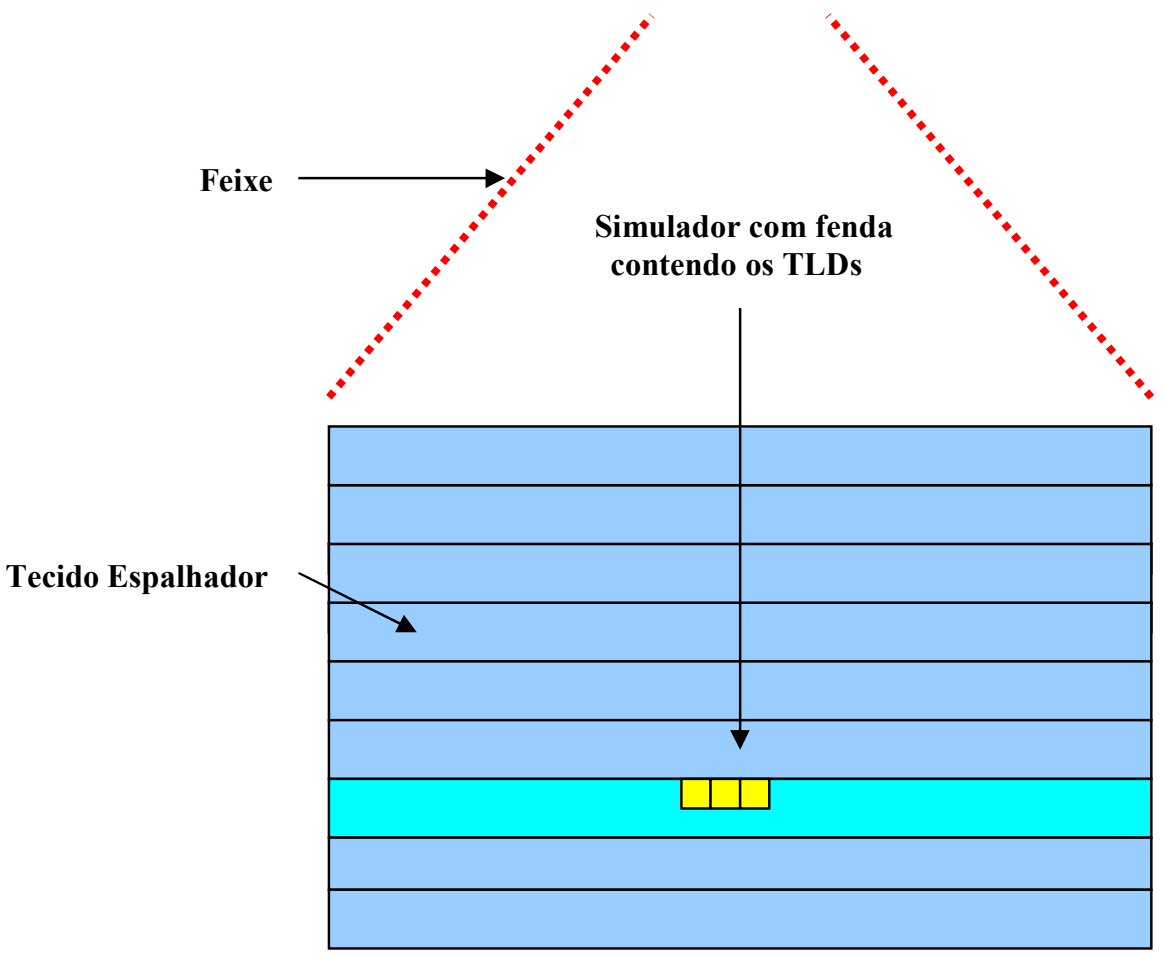

Figura 2.13- Esquema do arranjo usado para a medida da $D_{p}$, para uma situação na qual os $T L D s$ são irradiados aos $6 \mathrm{~cm}$ de profundidade. 


\section{CAPÍTULO 3}

\section{RESULTADOS E DISCUSSÕES}

Neste capítulo são apresentados, através de tabelas e gráficos, os resultados obtidos tanto na caracterização dos dosímetros empregados, quanto na determinação das grandezas dosimétricas de interesse em mamografia, juntamente com suas análises e comparações com as referências bibliográficas.

\subsection{Caracterização dos Dosímetros TLD-100}

\subsubsection{Homogeneidade de Grupo}

Os valores calculados mostram que os coeficientes de HG do conjunto inicial de 60 dosímetros utilizado neste trabalho, apenas 48 deles satisfazem o requerimento da norma IEC 1066, a qual estabelece que a homogeneidade de grupo deva ser menor ou igual a $30 \%$.

Procurando determinar a incerteza do resultado obtido neste teste, o procedimento mencionado na seção 2.7.1 foi repetido para o grupo de TLD's escolhidos mais quatro vezes, obtendo uma Homogeneidade de Grupo media com um valor de $(24,3 \pm 2,0) \%$. A norma IEC 1066 estabelece o 30\% como o máximo valor de aceitação para a homogeneidade de grupo.

\subsubsection{Reprodutibilidade}

Os dosímetros selecionados, além de apresentar flutuações nas respostas individuais menores ou iguais aos 30\% devem possuir uma ótima estabilidade nas suas respostas para repetidas irradiações, para tanto foi testada a reprodutibilidade dos 48 dosímetros selecionados depois do teste da HG. Em concordância com a norma IEC 1066, a reprodutibilidade individual de cada dosímetro foi analisada calculando-se o Coeficiente de 
Variação (CV), através da equação 2.2, para as cinco leituras. Os valores do CV calculados são mostrados na tabela 3.2 .

Tabela 3.1: Resultado do cálculo do coeficiente de variação (CV)

\begin{tabular}{|c|c|c|c|c|c|c|c|c|c|c|c|}
\hline TLD \# & $\mathrm{CV}$ & $\% \mathrm{CV}$ & TLD \# & $\mathrm{CV}$ & $\% \mathrm{CV}$ & TLD \# & $\mathrm{CV}$ & $\% \mathrm{CV}$ & TLD \# & $\mathrm{CV}$ & $\% \mathrm{CV}$ \\
\hline 1 & 0,069 & 6,9 & 13 & 0,022 & 2,2 & 25 & 0,060 & 6,0 & 37 & 0,058 & 5,8 \\
\hline 2 & 0,038 & 3,8 & 14 & 0,037 & 3,7 & 26 & 0,044 & 4,4 & 38 & 0,068 & 6,8 \\
\hline 3 & 0,071 & 7,1 & 15 & 0,062 & 6,2 & 27 & 0,041 & 4,1 & 39 & 0,073 & 7,3 \\
\hline 4 & 0,064 & 6,4 & 16 & 0,068 & 6,8 & 28 & 0,060 & 6,0 & 40 & 0,074 & 7,4 \\
\hline 5 & 0,051 & 5,1 & 17 & 0,051 & 5,1 & 29 & 0,072 & 7,2 & 41 & 0,073 & 7,3 \\
\hline 6 & 0,062 & 6,2 & 18 & 0,045 & 4,5 & 30 & 0,060 & 6,0 & 42 & 0,067 & 6,7 \\
\hline 7 & 0,063 & 6,3 & 19 & 0,075 & 7,5 & 31 & 0,076 & 7,6 & 43 & 0,054 & 5,4 \\
\hline 8 & 0,067 & 6,7 & 20 & 0,053 & 5,3 & 32 & 0,079 & 7,9 & 44 & 0,046 & 4,6 \\
\hline 9 & 0,049 & 4,9 & 21 & 0,061 & 6,1 & 33 & 0,071 & 7,1 & 45 & 0,021 & 2,1 \\
\hline 10 & 0,065 & 6,5 & 22 & 0,075 & 7,5 & 34 & 0,060 & 6,0 & 46 & 0,063 & 6,3 \\
\hline 11 & 0,059 & 5,9 & 23 & 0,078 & 7,8 & 35 & 0,065 & 6,5 & 47 & 0,049 & 4,9 \\
\hline 12 & 0,045 & 4,5 & 24 & 0,057 & 5,7 & 36 & 0,058 & 5,8 & 48 & 0,040 & 4,0 \\
\hline
\end{tabular}

A norma IEC 1066 sugere um coeficiente de variação $C V \leq 7,5 \%$. A tabela 3.2 apresenta dosímetros que possuem um valor de CV maior que a referência estabelecida na norma. Estes dosímetros foram excluídos do grupo.

Depois de realizados os testes de reprodutibilidade e homogeneidade de grupo, foram escolhidos apenas 45 dosímetros que apresentaram flutuações e estabilidade em suas respostas termoluminescentes, dentro dos limites de aceitação recomendados pela norma da IEC 1066, e no caso da $\mathrm{HG}$, dentro do limite estabelecido neste trabalho.

\subsubsection{Determinação do Fator de Calibração}

A tabela 3.3 apresenta o fator de calibração $\left(f_{c}\right)$, obtido através das equações 2.4 e 2.5 , para cada um dos dosímetros selecionados apôs os testes de HG e reprodutibilidade. 
Tabela 3.2: Resultado do cálculo do fator de calibração $f_{c} \operatorname{dos} T L D s$

\begin{tabular}{|c|c|c|c|c|c|c|c|}
\hline TLD & $f_{c}$ & TLD & $f_{c}$ & TLD & $f_{c}$ & TLD & $f_{c}$ \\
\hline 1 & $0,639 \pm 0,005$ & 13 & $0,624 \pm 0,001$ & 25 & $0,622 \pm 0,003$ & 37 & $0,654 \pm 0,004$ \\
\hline 2 & $0,646 \pm 0,006$ & 14 & $0,649 \pm 0,002$ & 26 & $0,646 \pm 0,003$ & 38 & $0,685 \pm 0,003$ \\
\hline 3 & $0,616 \pm 0,004$ & 15 & $0,645 \pm 0,004$ & 27 & $0,642 \pm 0,002$ & 39 & $0,648 \pm 0,004$ \\
\hline 4 & $0,639 \pm 0,003$ & 16 & $0,607 \pm 0,003$ & 28 & $0,652 \pm 0,004$ & 40 & $0,674 \pm 0,004$ \\
\hline 5 & $0,621 \pm 0,003$ & 17 & $0,646 \pm 0,003$ & 29 & $0,696 \pm 0,003$ & 41 & $0,619 \pm 0,004$ \\
\hline 6 & $0,646 \pm 0,003$ & 18 & $0,609 \pm 0,002$ & 30 & $0,566 \pm 0,003$ & 42 & $0,649 \pm 0,003$ \\
\hline 7 & $0,612 \pm 0,003$ & 19 & $0,624 \pm 0,004$ & 31 & $0,633 \pm 0,004$ & 43 & $0,642 \pm 0,004$ \\
\hline 8 & $0,644 \pm 0,003$ & 20 & $0,715 \pm 0,003$ & 32 & $0,676 \pm 0,004$ & 44 & $0,623 \pm 0,002$ \\
\hline 9 & $0,640 \pm 0,004$ & 21 & $0,636 \pm 0,008$ & 33 & $0,618 \pm 0,004$ & 45 & $0,626 \pm 0,004$ \\
\hline 10 & $0,610 \pm 0,004$ & 22 & $0,586 \pm 0,004$ & 34 & $0,566 \pm 0,004$ & & \\
\hline 11 & $0,633 \pm 0,003$ & 23 & $0,627 \pm 0,004$ & 35 & $0,636 \pm 0,004$ & & \\
\hline 12 & $0,646 \pm 0,007$ & 24 & $0,575 \pm 0,003$ & 36 & $0,617 \pm 0,003$ & & \\
\hline
\end{tabular}

Dos dosímetros analisados foram selecionados somente aqueles que apresentaram variação de até $3 \%$ em relação ao valor médio dos fatores de calibração apresentados na tabela 3.3. Para estes dosímetros selecionados, cada vez que foram realizadas as novas irradiações, foram escolhidos aleatoriamente cinco dosímetros para refazer o cálculo do $f_{c}$, cujo valor médio foi utilizado para calcular os valores de dose a partir das leituras registradas para cada dosímetro.

\subsubsection{Linearidade}

Através da equação 2.7, a norma IEC 1066 sugere o critério de avaliação a utilizar no teste de linearidade. O critério de avaliação estabelece que a resposta dos dosímetros relacionada a dose entregada não deve variar por mais dos $10 \%$ sobre o intervalo de $0,1 \mathrm{mSv}$ até $1 \mathrm{~Sv}$ (10mrem-100rem) (VELBECK et al., 1999). 
Considerando este intervalo de aceitação, o máximo valor obtido dentre os diferentes valores de dose entregada neste teste foi:

\section{$0,90<1,088<1,10$}

A linearidade foi avaliada para valores de dose no intervalo de $0,5 \mathrm{mGy}$ até $10 \mathrm{mGy}$, abrangendo assim os valores característicos usados nos principais exames mamográficos, como é observado na figura 3.1 .

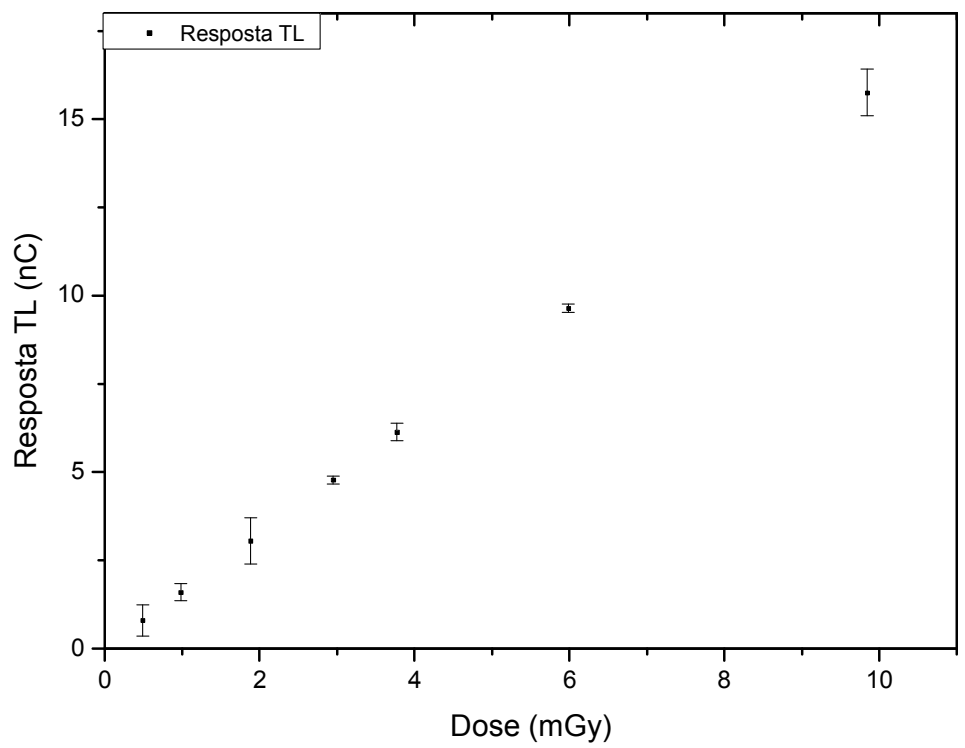

Figura 3.1: Curva de Resposta TL em função da Dose

A figura 3.1 permite observar que os TLDs utilizados apresentam uma resposta linear para o intervalo de dose empregado neste trabalho. A resposta obtida neste teste era esperada, reiterando o apresentado por CAMMERON (1968), que mostrou que os TLD-100 apresentam uma resposta TL linear para doses no intervalo de $10^{-1} \mathrm{mGy}$ até $10^{2} \mathrm{mGy}$.

\subsubsection{Dependência Energética}

A figura 3.2 apresenta os valores experimentais obtidos na determinação da resposta relativa em função da energia do feixe; os pontos pretos representam os fatores de 
dependência energética obtidos experimentalmente em tanto que os vermelhos ao valor calculado através da equação 2,8 .

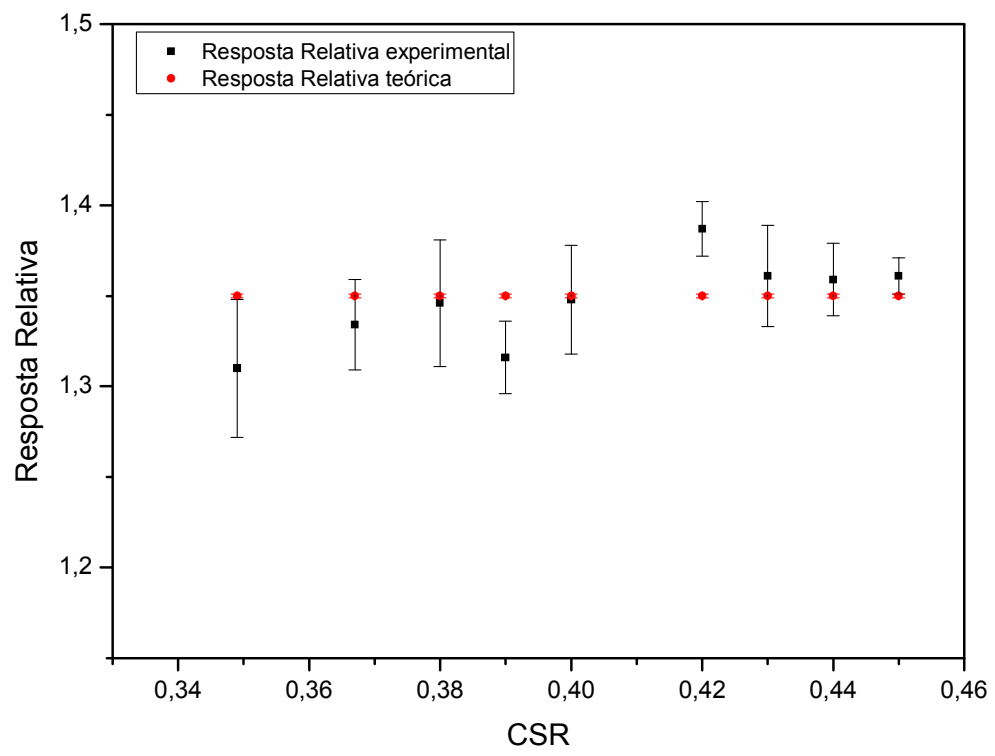

Figura 3.2: Resposta Relativa em função da energia do feixe.

Os resultados obtidos mostram que os dosímetros utilizados apresentam uma resposta relativa média igual à $(1,34 \pm 0,05)$ na faixa energética usada neste estudo.

Utilizando a expressão teórica (equação 2.8) e os valores dos coeficientes médios de absorção em massa do $\mathrm{LiF}$ e do Ar para as energias efetivas correspondente às respectivas CSR (BERGER et al., 2005), o valor médio encontrado foi de $(1,35 \pm 0,01)$.

Isto mostra que os dosímetros apresentam uma resposta relativa a ser levada em conta na determinação da dose de entrada na pele (COSTA, 2008).

\subsection{Determinação da Dose de Entrada na Pele}

Utilizando os simuladores mamários semicilíndricos de PMMA, foram determinados os valores de dose de entrada na pele, para diferentes espessuras do simulador mamário e condições clínicas de mamografia avaliadas neste trabalho, obtidas variando a combinação ânodo-filtro e a tensão do tubo de raios X. 
Os valores obtidos na determinação da dose de entrada na pele através de $T L D$ são apresentados na figura 3.3.

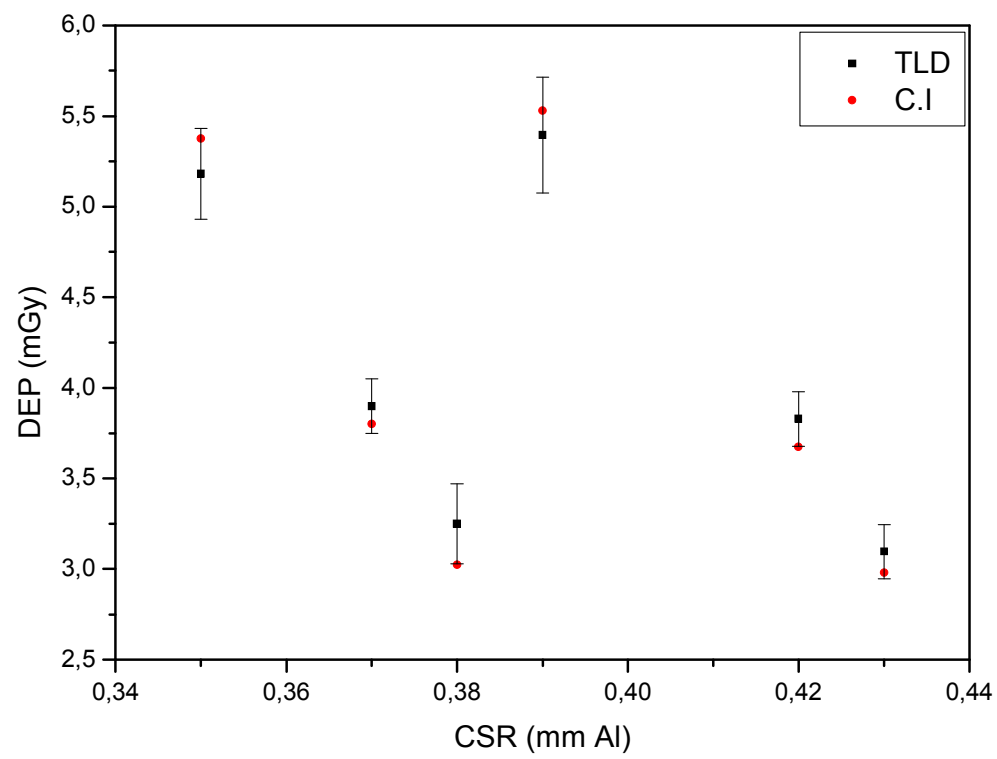

Figura 3.3: $D E P$ como função da CSR para um simulador mamário de PMMA de $6 \mathrm{~cm}$ de espessura utilizando as combinações Mo-Mo e Mo-Rh e tensão do tubo igual aos $28 \mathrm{kV}, 30 \mathrm{kV}$ e $32 \mathrm{kV}$.

Na figura também aparecem os valores da $D E P$ obtidos utilizando uma câmara de ionização (c.i). Estes valores foram determinados utilizando os valores de $B S F$ recomendados pelo European Protocolo on Dosimetry in Mammography.(KRAMER, 2000).

As incertezas associadas às determinações realizadas com os dosímetros TL representam, em média, $5 \%$ da grandeza obtida, enquanto as obtidas com a câmara de ionização representam em média $2 \%$. Esse resultado era esperado devido ao maior número de fontes de erro envolvido nas medidas realizadas com os $T L D s$ comparadas com as realizadas utilizando a câmara de ionização

Os valores para a $D E P$ determinados através das medidas com TLD apresentam uma boa concordância com obtidos utilizando uma câmara de ionização (diferenças menores que 4\%), para iguais valores de espessura do simulador, como apresentado na figura 3.4. Este resultado permite sugerir a utilização dos TLD-100, previamente caracterizados e selecionados, como alternativa na determinação da $D E P$ para estudos clínicos. 


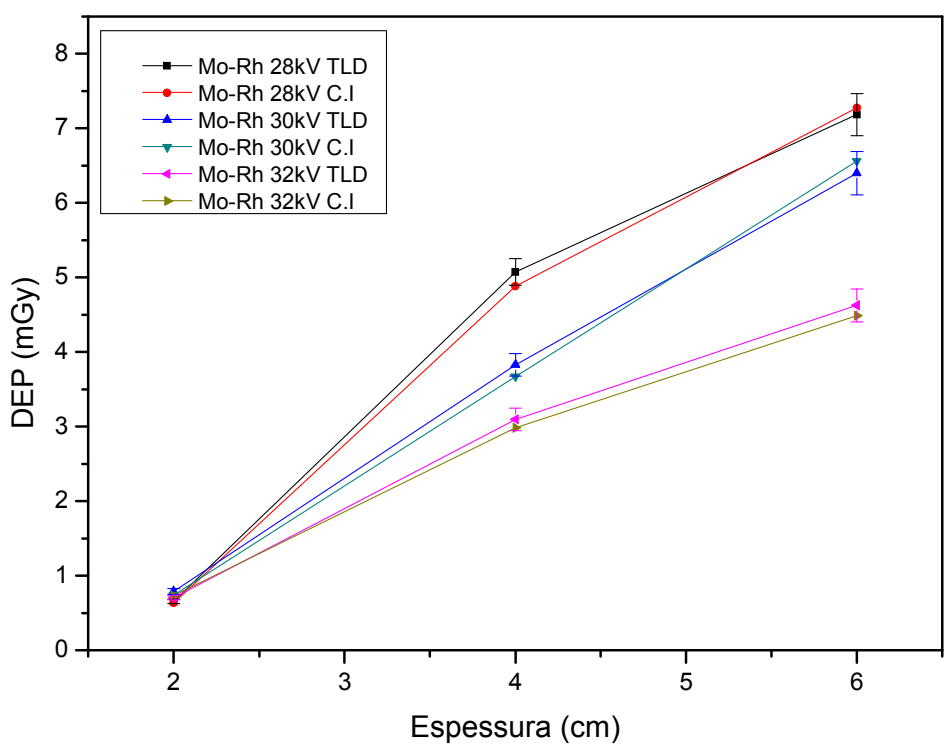

Figura 3.4: DEP como função da espessura para diferentes valores de tensão do tubo, e o tamanho do campo de $18 \mathrm{~cm} \times 24 \mathrm{~cm}$.

É possível ver nas figuras 3.3 e 3.4 que os valores de $D E P$ obtidos, estão dentro da tolerância presente na norma da ANVISA, a qual estabelece como referência, que para uma mama de 4,5cm de espessura, a $D E P$ deve ser menor ou igual aos $10 \mathrm{mGy}$. Uma mama de essa espessura é equivalente a uma espessura de $4 \mathrm{~cm}$ do simulador mamário semicilíndrico de PMMA (DANCE, 2000).

\subsection{Determinação do Fator de Retroespalhamento}

Os fatores de retroespalhamento $(B S F)$ obtidos experimentalmente são apresentados nesta seção. Primeiramente serão mostrados os valores dos fatores de retro espalhamento obtidos variando as condições geométricas de exposição, e posteriormente são apresentados os valores de $B S F$ obtidos variando as condições energéticas. 


\subsubsection{Fator de Retroespalhamento: Dependências Geométricas}

\subsubsection{Fator de Retroespalhamento em função da espessura do simulador mamário}

Os resultados obtidos na determinação da dependência do $B S F$ como função da espessura do simulador mamário semicilindrico de PMMA são apresentados na figura 3.5:

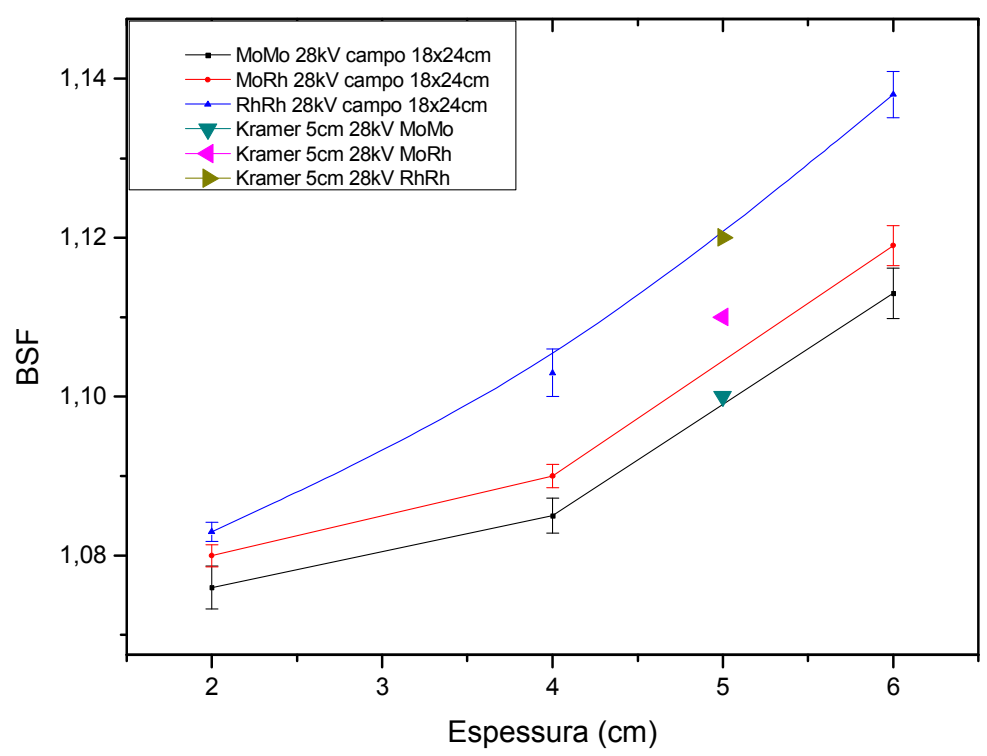

Figura 3.5: $B S F$ em função da espessura do simulador mamário para todas as combinações ânodo-filto, campo de $18 \mathrm{~cm} \times 24 \mathrm{~cm}$ e $28 \mathrm{kV}$.

Observa-se da figura, que os valores do $B S F$ aumentam com a espessura do simulador, para cada uma das combinações ânodo-filtro, utilizando a mesma tensão e mesmo tamanho de campo.

A percentagem de incremento no valor do $B S F$, em média, corresponde ao $1 \%$ por cada centímetro de aumento da espessura do simulador, o qual é um resultado esperado pelo fato da intensidade de fótons espalhados aumentarem com a espessura (volume) do tecido espalhador. Este comportamento também foi observado por CHAN (1981), através de cálculos utilizando simulação Monte Carlo.

Tendências similares foram encontradas para os outros valores de $B S F$ correspondentes às outras tensões de tubo e tamanhos de campo avaliados neste trabalho. 
$\mathrm{Na}$ figura também são mostrados três pontos (forma de triângulo), os quais foram obtidos por simulação Monte Carlo por KRAMER (2000), para um simulador mamário de PMMA de $5 \mathrm{~cm}$ de espessura. Pode-se observar uma boa concordância entre os resultados obtidos neste trabalho e os valores obtidos por KRAMER (2000).

\subsubsection{Fator de Retroespalhamento em função do Tamanho da área irradiada.}

No estudo da relação entre o $B S F$ e o tamanho da área irradiada, foram utilizados os três tamanhos de campo $(9 \mathrm{~cm} \times 9 \mathrm{~cm} ; 13 \mathrm{~cm} \times 18 \mathrm{~cm}$ e $18 \mathrm{~cm} \times 24 \mathrm{~cm})$ que permite o mamógrafo do Hospital das Clínicas da Faculdade de Medicina de Ribeirão Preto (FMRP)-USP, e os dois tipos de formatos dos simuladores mamários de PMMA (semicilíndrico e paralelepípedo), correspondendo às áreas irradiadas de $81 \mathrm{~cm}^{2}, 234 \mathrm{~cm}^{2}$, e $432 \mathrm{~cm}^{2}$ respectivamente, para o formato paralelepípedo e $157 \mathrm{~cm}^{2}$ para o semicilindrico, todos com $4 \mathrm{~cm}$ de espessura. A figura 3.6 apresenta os resultados obtidos:

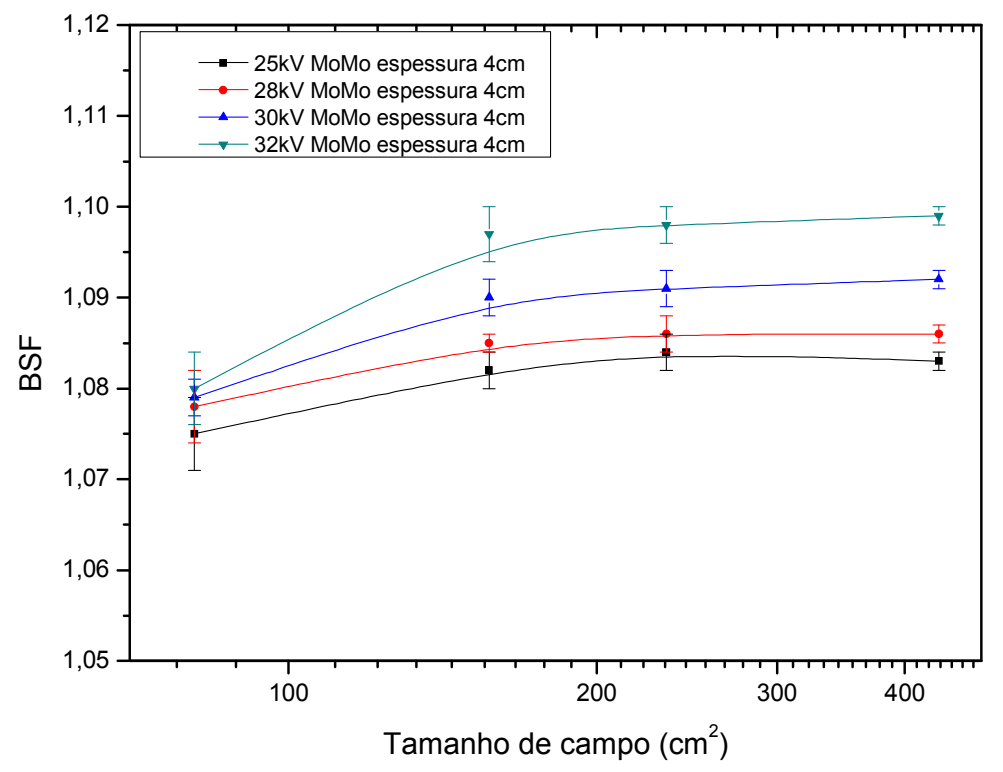

Figura 3.6: $B S F$ em função do tamanho do campo de radiação, para simuladores semicilíndricos e de $30 \mathrm{~cm} \times 30 \mathrm{~cm}$ de PMMA com espessura de $4 \mathrm{~cm}$. 
Os gráficos correspondentes às outras espessuras apresentaram tendências similares à mostrada na figura 3.6, resultados os quais coincidem com as tendências apresentadas nos trabalhos de DUBUQUE (1977), KLEVENHAGEN (1989), GROSSWENDT (1990), e do KLEVENHAGEN (1991).

Tanto nos resultados obtidos neste trabalho como em aqueles apresentados na literatura, pode-se observar que os valores de $B S F$ alcançam uma saturação ao aumentar o valor da área irradiada. Neste estudo a saturação foi alcançada aproximadamente aos 200 $\mathrm{cm}^{2}$. Este fato pode ser explicado pela leve dependência da intensidade espalhada com a área irradiada (BARNES, 1991), já que o TLD é sensível ao seu entorno próximo e não a pontos muito distantes de onde ele é posicionado.

\subsubsection{Fator de Retroespalhamento em função da distancia foco- superfície}

Foram utilizados valores da distancia foco-superficie iguais a $56 \mathrm{~cm}, 61 \mathrm{~cm}$ e $66 \mathrm{~cm}$. Os resultados obtidos são apresentados na figura 3.7 .

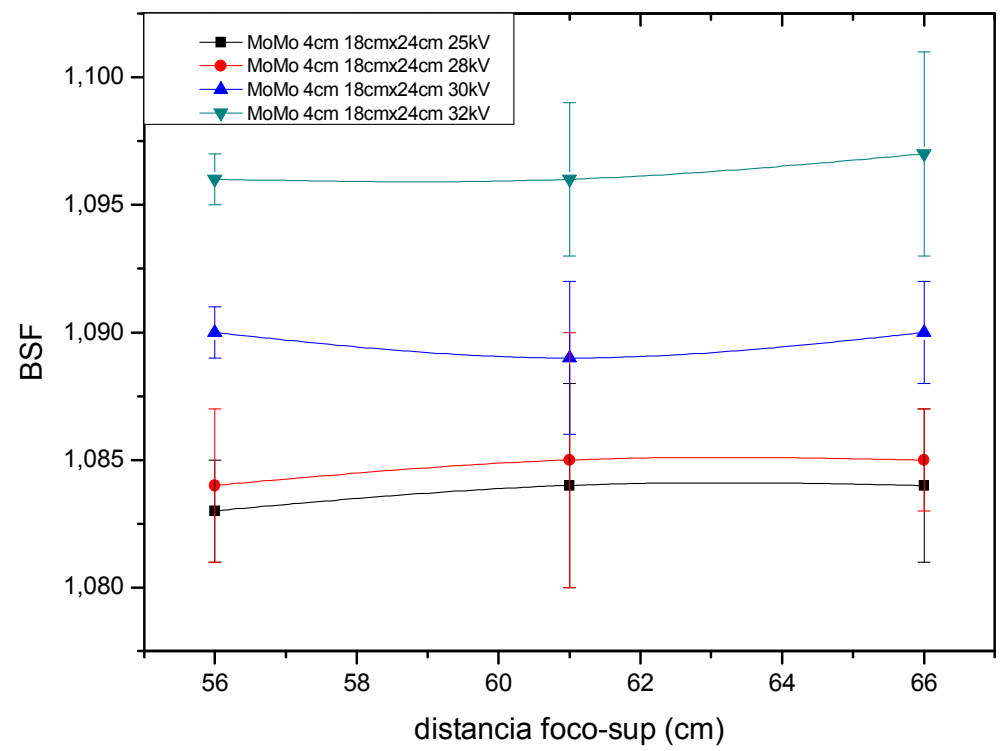

Figura 3.7: $B S F$ em função da distancia foco-superficie. Usando uma combinação Mo-Mo, simulador de $4 \mathrm{~cm}$ de espessura, campo de $18 \mathrm{~cm} \times 24 \mathrm{~cm}$, e $28 \mathrm{kV}$. 
Os dados obtidos indicam que ao variar a distancia foco-superficie os valores de $B S F$ não apresentam uma variação significativa. Estes resultados eram esperados uma vez que ao mesmo tempo em que a radiação incidente aumenta (com a diminuição da distancia focosuperfície) a radiação espalhada aumenta, compensado o aumento anterior. Estes resultados concordam com os obtidos por GROSSWENDT (1990), e com os apresentados por KLEVENHAGEN (1991) para raios X de baixas energias.

Os resultados obtidos para outros valores de tensão, e combinações ânodo-filtro avaliadas neste trabalho apresentaram comportamentos similares aos mostrados na figura 3.7.

\subsubsection{Fator de Retro espalhamento: Dependências Energéticas}

Além de estudar as dependências geométricas do $B S F$, neste trabalho também foram estudadas suas dependências espectrais, entre as quais foram consideradas: a camada semiredutora (CSR), a combinação ânodo-filtro, e tensão do tubo de raios X. Nas seguintes secções são apresentados os resultados obtidos.

\subsubsection{Fator de Retroespalhamento em Função da Camada Semi-Redutora}

Os resultados obtidos ao estudar a dependência do $B S F$ com a CSR são apresentados na figura 3.8 . 


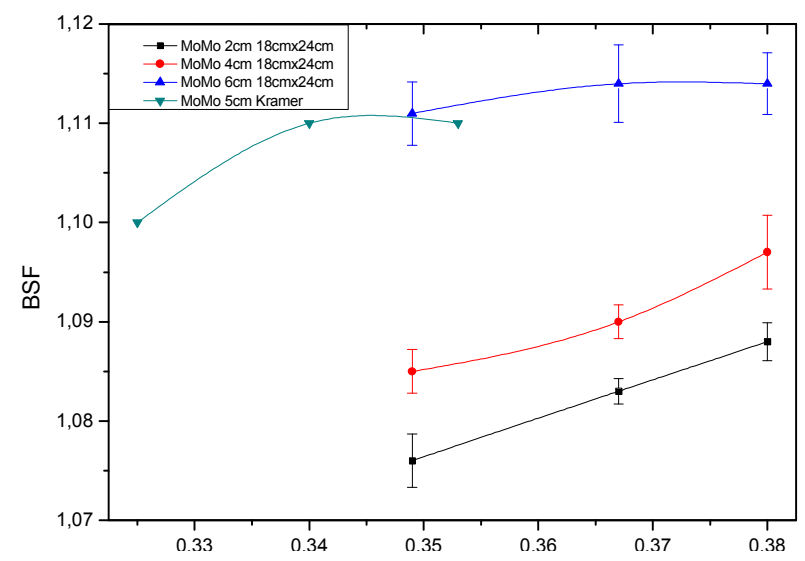

Figura 3.8: $B S F$ vs CSR para todas as espessuras, combinação Mo-Mo e campo $18 \mathrm{~cm} \times 24 \mathrm{~cm}$.

Esta figura mostra que o valor do $B S F$ para cada espessura, aumenta com a CSR, o qual pode-se explicar pelo fato que feixes com maior CSR apresentam uma energia efetiva maior e, portanto, teriam mais probabilidade de sofrer interações de espalhamento (retroespalhar) que aqueles feixes de menor qualidade. Esta dependência faz que geralmente os valores do BSF sejam tabulados ou graficados como função da CSR.

Para as outras combinações ânodo-filtro, e os outros tamanhos de campo avaliados, foram encontrados comportamentos similares aos mostrado na figura 3.8.

A figura 3.9 compara os resultados obtidos no presente trabalho com aqueles apresentados na bibliografia. 


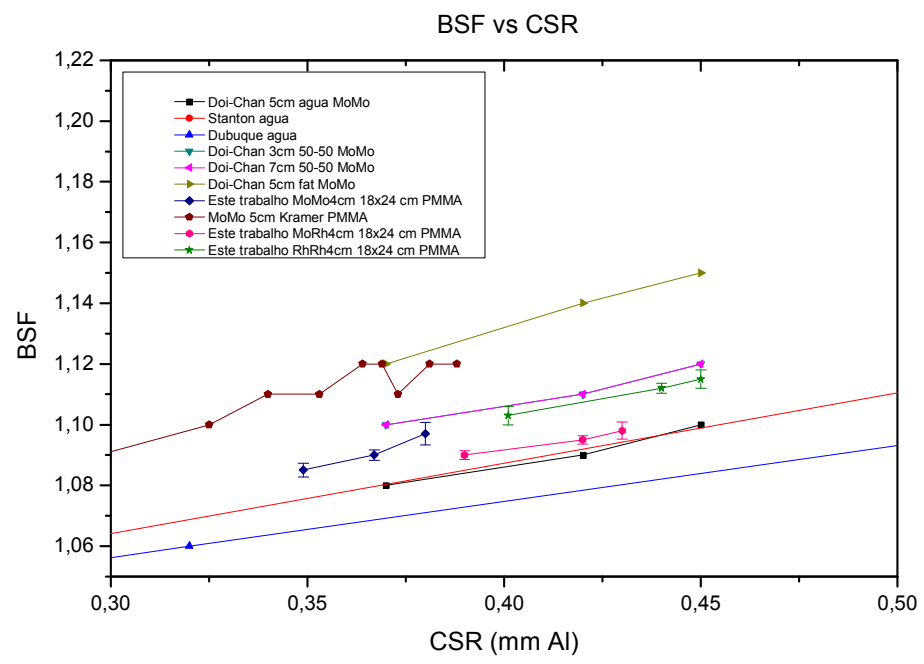

Figura 3.9: $B S F$ vs CSR, comparação entre os resultados obtidos neste trabalho e as referências bibliográficas.

As curvas obtidas no presente trabalho apresentam comportamentos similares aos encontrados na literatura, embora aqueles trabalhos utilizarem espessuras e composição diferentes, inclusive diferentes metodologias para obtenção dos valores de BSF. Todos apresentam dependência com a CSR, aumentando o $B S F$ conforme aumenta a energia efetiva do feixe.

As diferenças entre os valores absolutos obtidos neste estudo e os apresentados na literatura (DUBUQUE, 1977; DOI, 1980; CHAN, 1981; STANTON, 1981; GROSSWENDT, 1984; KLEVENHAGEN, 1989; KRAMER, 2000) devem-se principalmente a diferenças espectrais. A utilização de espectros diferentes pode produzir diferenças até $3 \%$ (GROSSWENDT, 1990); também às limitações geométricas inerentes às medidas realizadas com dosímetros, como a área finita dos TLDs (STANTON, 1981), às espessuras diferentes utilizadas em cada trabalho, e a incertezas introduzidas na base de dados utilizadas nas simulações (DOI, 1980) tem influencia nas diferencias dos resultados obtidos. 


\subsubsection{Fator de Retroespalhamento como função da combinação ânodo-filtro}

A dependência do $B S F$ com a combinação ânodo-filtro foi avaliada para diferentes espessuras, tensões do tubo, e diferentes tamanhos de campo. A figura 3.10 mostra os resultados obtidos.

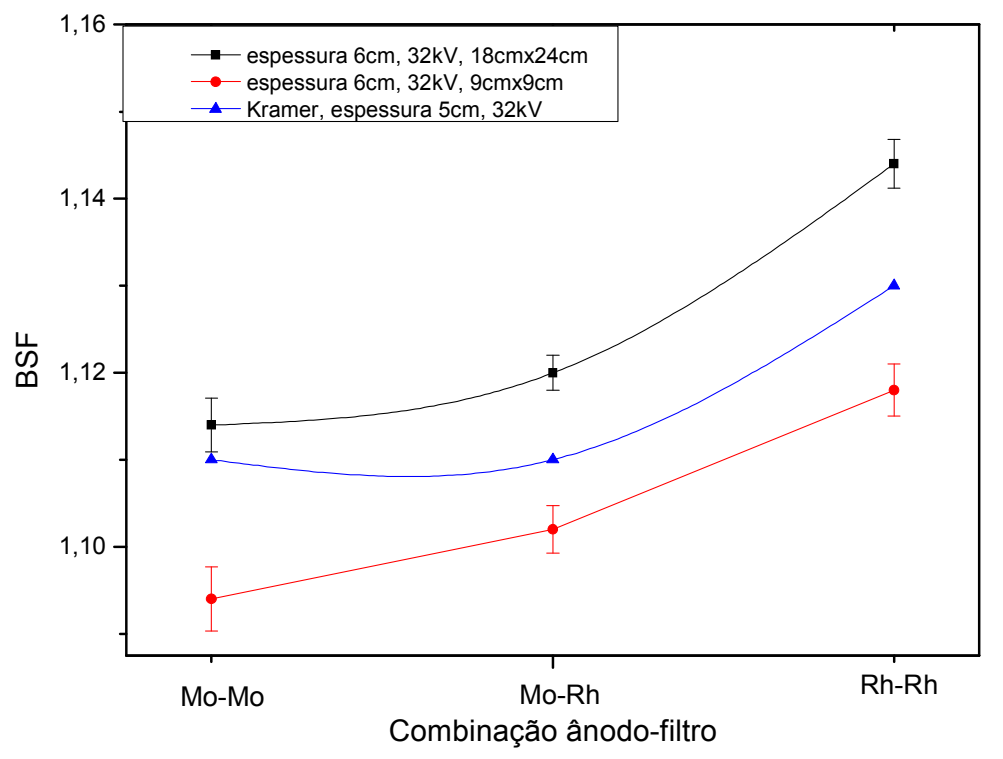

Figura 3.10: $B S F$ como função da combinação ânodo-filtro, para simulador semicilindricos de $6 \mathrm{~cm}$ de espessura, $32 \mathrm{kVp}$ no tubo e campos de $9 \mathrm{~cm} \times 9 \mathrm{~cm}$ e $18 \mathrm{~cm} \times 24 \mathrm{~cm}$.

Os resultados obtidos neste trabalho concordam com os apresentados por KRAMER (2000), mostrando um aumento dos valores do BSF ao mudar de uma combinação Mo-Mo, para Mo-Rh e para Rh-Rh para uma mesma espessura e tensão do tubo. Em média, observouse um incremento de $1 \%$ ao passar da combinação Mo-Mo para Mo-Rh e 1,5\% ao passar de Mo-Rh para Rh-Rh. KRAMER (2000) apresenta em média um aumento de 0,6\% para a primeira passagem (Mo-Mo para Mo-Rh), e 1,5\% para a segunda. A explicação para este fato baseia-se, também, no aumento da energia efetiva do feixe, para uma mesma tensão do tubo, ao passar de uma combinação para a outra.

Nesta secção a comparação foi realizada apenas com o trabalho de KRAMER (2000), por ser o único trabalho publicado no qual foi considerada esta dependência. 


\subsubsection{Fator de Retroespalhamento em função da Tensão do Mamógrafo}

A figura 3.11 apresenta um exemplo típico da dependência do BSF com a tensão do tubo de raios $\mathrm{X}$ :

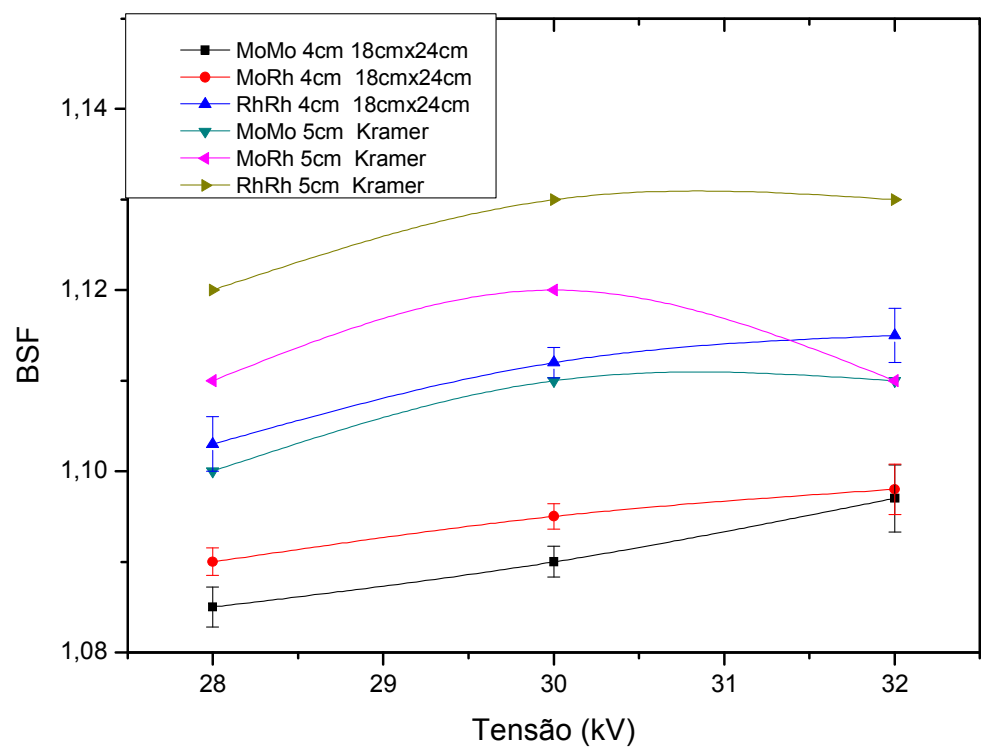

Figura 3.11: $B S F$ como função do $k V p$ do tubo de raios $\mathrm{x}$, combinação $\mathrm{Mo} / \mathrm{Mo}$, simulador de $4 \mathrm{~cm}$ de espessura e campo de $18 \mathrm{~cm} \times 24 \mathrm{~cm}$.

Nesta figura se pode observar que os valores de $B S F$ aumentam levemente ao se incrementar os valores de tensão do tubo, 0,5\% para cada $1 \mathrm{kV}$ de incremento dentro do intervalo de tensão avaliado. Este resultado era esperado pelo fato do aumento da probabilidade de interação por espalhamento com o aumento da energia dos fótons. Similares tendências apresentaram as curvas obtidas para as outras espessuras avaliadas neste estudo.

Este comportamento (leve aumento com a $k V p$ ) concorda com os resultados apresentados por KRAMER (2000), obtidos por simulação Monte Carlo para o mesmo intervalo de valores de tensão do tubo utilizados neste trabalho. Entretanto, os valores absolutos apresentam diferenças causadas pelas razoes anteriormente citadas na seção 3.3.2.1.

É importante mencionar que o trabalho de HARRISON (1982) apresenta resultados nos quais o $B S F$ aumenta levemente também ao se incrementar a tensão do tubo de raios $\mathrm{x}$ 
para CSR no intervalo de $1 \mathrm{~mm} \mathrm{Al}$ a $3 \mathrm{~mm} \mathrm{Al}$, entretanto o aumento é significativo para grandes variações de tensão (KLEVENHAGEN, 1991).

\subsection{Determinação da Dose em Profundidade}

Conhecer o comportamento da dose absorvida nas distintas profundidades do tecido espalhador é importante para estudar e modelar o risco de carcinogênese em mamografia.

Nas secções seguintes foram medidas as doses absorvidas pelos dosímetros TL posicionados dentro do simulador mamário, em profundidades de $1 \mathrm{~cm}$ até $8 \mathrm{~cm}$, utilizando os valores de tensão do tubo, assim como as combinações ânodo-filtro avaliados neste trabalho.

\subsubsection{Dose em Profundidade em função da Tensão do Mamógrafo}

Os valores da dose relativa absorvida em profundidade pelo material do simulador semicilíndrico, para $28 \mathrm{kVp}$ e $32 \mathrm{kVp}$, são apresentados na figura 3.12 juntamente com os obtidos por Hammerstein et al. (1979) para tecido adiposo, e para um feixe com 0,36 mmAl de CSR. 


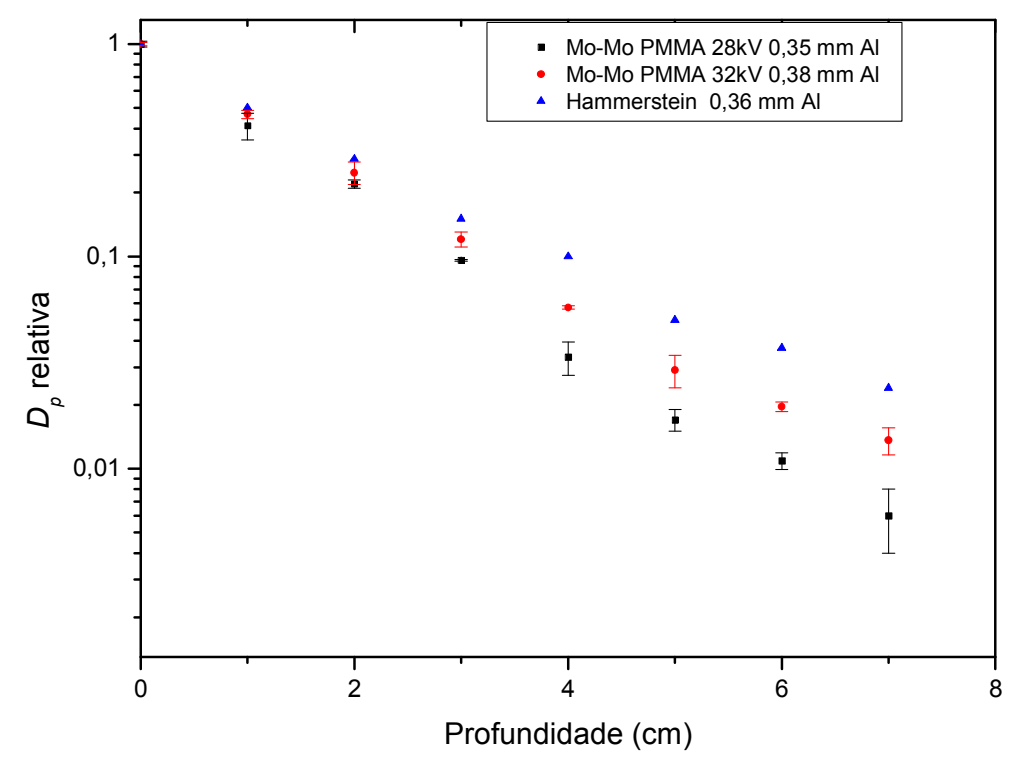

Figura 3.12: Dose em função da profundidade para valores da tensão do tubo de $28 k V$ e $32 k V$.

A figura 3.12 mostra que os valores de dose decrescem exponencialmente ao aumentar a profundidade de penetração no simulador, o qual é decorrente da atenuação sofrida pela energia radiante do feixe conforme penetra no material (coeficiente de absorção de energia).

$\mathrm{Da}$ mesma forma este fato justifica a dependência dos coeficientes angulares das curvas apresentadas com a tensão do tubo, uma vez que feixes mais energéticos apresentam menores absorções.

As tendências observadas neste trabalho concordam com as apresentadas na literatura (HAMMERSTEIN, 1979; STANTON et al., 1981; STANTON, 1984). Entretanto, as diferenças, em valores absolutos, devem-se principalmente ao tipo (composição) de material utilizado na realização das medidas.

\subsubsection{Dose em Profundidade em função da combinação ânodo-filtro}

Fixando o tamanho do campo e a tensão do tubo, foram obtidos os valores da $D_{p}$, para as diferentes combinações ânodo-filtro. Na figura 3.13 são apresentados os valores da $D_{p}$ obtidos. 


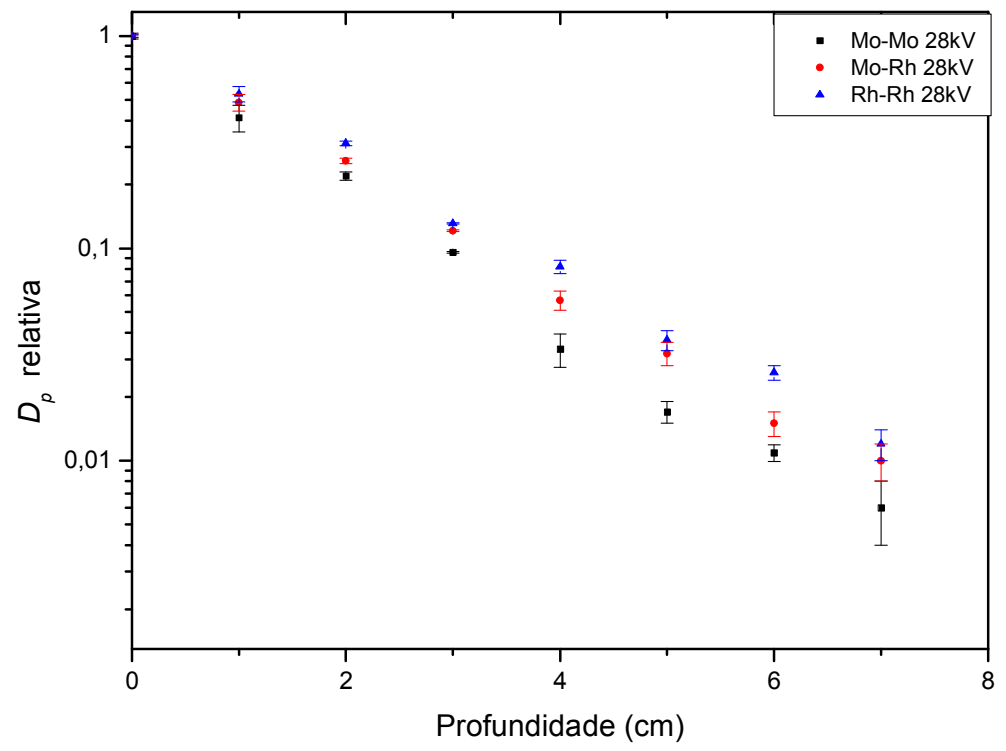

Figura 3.13: Dose em função da profundidade para as diferentes combinações ânodo-filtro avaliadas.

Tendências similares foram encontradas para as outras tensões do tubo avaliadas neste trabalho. Em geral, em todos eles a dose em profundidade relativa diminui exponencialmente, sendo as inclinações mais pronunciadas para a combinação Mo-Mo e menos pronunciadas para a Rh-Rh, este comportamento deve-se a dependência da absorção da energia do feixe com a energia efetiva do feixe, como explicado na seção 3.4.1. Neste caso, não é feita nenhuma comparação com trabalhos anteriores, uma vez que até o momento não existem trabalhos que estudaram esta dependência. 


\section{CAPÍTULO 4}

\section{CONCLUSÕES}

\subsection{Sobre a utilização dos TLD-100 na determinação das grandezas dosimétricas}

Dosímetros termoluminescentes de $\mathrm{LiF}, T L D-100$, foram utilizados neste trabalho para determinar a dose de entrada na pele, o fator de retroespalhamento, e a dose em profundidade.

Os resultados obtidos revelaram que os TLDs representam uma boa alternativa para medir in situ essas grandezas. Entretanto é importante destacar que para obter estes resultados é preciso fazer uma cuidadosa seleção dos $T L D s$, também requerem de um manuseio cuidadoso tanto na sua leitura, como no tratamento térmico, pré e pos-irradiação para garantir medições precisas (STANTON et. al. 1984). A recalibração periódica dos dosímetros é outro aspecto importante a ser levado em conta durante a realização das medições.

\subsection{Sobre a determinação da $D E P$}

Foram encontradas diferenças percentuais máximas de 4\% quando comparadas as $D E P$ obtidas através da câmara de ionização com as determinadas com TLDs. Resultados similares, utilizando TLDs, foram apresentados por STANTON et al.,1981.

Os resultados mostram que valores da $D E P$ diminuem, para uma combinação ânodofiltro e espessura fixas, conforme aumenta a energia efetiva do feixe ao aumentar a tensão do tubo. . A combinação Mo-Mo apresentou os maiores valores de $D E P$, em tanto que a combinação $\mathrm{Rh}-\mathrm{Rh}$ evidenciou os menores valores de $D E P$ ao fixar a espessura do simulador e a tensão do tubo. 


\subsection{Sobre as dependências geométricas do $B S F$}

Este trabalho investigou as dependências geométricas do $B S F$ variando a espessura do simulador mamário, o tamanho da área irradiada, e a distancia foco-superficie. A partir dos resultados obtidos, observou-se que o $B S F$ tem um incremento no seu valor em média do $1 \%$ ao se incrementar a espessura do simulador em $1 \mathrm{~cm}$. Concordando estes resultados com as estimativas publicadas por CHAN e DOI, 1981, obtidas por simulação Monte Carlo. Os valores obtidos de $B S F$ em função da área irradiada mostram que estes alcançam uma saturação para áreas maiores de $200 \mathrm{~cm}^{2}$, em conformidade com os resultados obtidos por STANTON 1981, GROSSWENDT 1983, KLEVENHAGEN 1989, e no IPSM Report 1991, entre outros.

A análise da dependência de $B S F$ com a distância foco-superficie mostrou que não há uma dependência significativa deste parâmetro na faixa de energia empregada em mamografia, comportamento similar a estes foram apresentados por HAMMERSTEIN 1979, GROSSWENDT 1990, e do IPSM Report 1991, entre outros.

\subsection{Sobre as dependências espectrais do $B S F$}

A partir dos resultados obtidos, observou-se que os valores de $B S F$, apresentam um aumento com o incremento dos valores da CSR na faixa de energias avaliadas, em concordância com DUBUQUE 1977, DOI 1980, CHAN 1981, STANTON et. al 1981, entre outros.

Também foi evidenciada uma dependência do $B S F$ com a combinação ânodo-filtro do mamógrafo, em concordância com os resultados do KRAMER 2000. Encontrando-se valores menores de $B S F$ para a combinação Mo-Mo e o maiores para Rh-Rh.

Todos estes resultados podem ser explicados pelo aumento da energia efetiva do feixe com a CSR, tensão do tubo, e mudança da combinação Mo-Mo para Rh-Rh.

Os valores obtidos de $B S F$ como função da tensão do mamógrafo permitiram verificar que existe uma leve dependência entre ambos. Observou-se um incremento, em média de 0,5\%, nos valores de $B S F$ por cada $k V$ de aumento na tensão do tubo, dentro do intervalo de 
tensões do mamógrafo avaliados; uma tendência similar com o apresentado por Klavenhagen no IPSM Report 1991, e por KRAMER 2000.

\subsection{Sobre a determinação de $D_{p}$}

Com base aos resultados obtidos, para cada tamanho do campo avaliado, observou-se um decaimento exponencial da dose relativa absorvida ao se incrementar a profundidade. Os feixes que apresentam uma maior energia efetiva resultam numa constante de atenuação menor. Nos gráficos de dose em função da profundidade, as inclinações mais pronunciadas correspondem à combinação Mo-Mo (menos energética), entanto que para Rh-Rh (a mais energética) resultaram menos pronunciadas. Os resultados encontrados estão dentro das estimativas publicadas por HAMMERSTEIN 1979, STANTON et al.1981, STANTON 1984, e KRAMER 2000, entre outros. 


\section{REFERÊNCIAS BIBLIOGRÁFICAS}

ATTIX, F. H. Introduction to radiological physics and radiation dosimetry. A Wiley. Interscience Publication, Madison, Wiscosin, 1986.

BARNES, G.T. Contrast and Scatter in X-ray imaging. Radiographics 11: 307, 1991.

BERGER M.J., HUBBELL J.H. XCOM: Photon Cross Sections Database. Web version 1.2. National Institute of Standards and Technology, Gaithersburg, MD 20899, USA, August 1999. Disponível em: http://physics.nist.gov/xcom. Originalmente publicado como NBSIR 87-3597, XCOM: Photon Cross Sections on a Personal Computer (1987)

CAMMERON J.R \& SKOFRONIC, J.G. Medical Physics. Wiley Interscience, 1978.

CAMMERON, J. R; SUNTHARALINGAM, N.; KENNEY, G. N. Thermoluminescent Dosimetry. The University of Wisconsin Press, 1968.

CARLSSON C.A. Differences in reported backscatter factors for low-energy x-rays: a literature study. Physics in Medicine and Biology 38: 521-531, 1993.

CARLSSON C.A.; MARTENSON B.K; CARLSSON A. High precision dosimetry using thermoluminescent LiF. USAEC Report CONF-680920: 936-939, 1968.

COSTA A., CALDAS L.V.E. Câmara de ionização de placas paralelas para radiação-x de radiografia convencional e mamografía. Radiologia Brasileira 41(1). 2008.

CHAN H., DOI K. Monte Carlo Simulation Studies of Backscatter Factors in Mammography. Radiology 139: 195-199, 1981.

DANCE D. R, SKINNER C.L, YOUNG K.C, BECKETT J.R,KOTRE C.J. Additional factors for the estimation of mean glandular breast dose using the UK mammography dosimetry protocol Physics in Medicine and Biology 45:3225-3240, 2000 
DOI K., CHAN H. Evaluation of absorbed dose in mammography: Monte Carlo simulation studies. Radiology 135: 199-208, 1980.

GROSSWENDT B. Backscatter factor for x-rays generated at voltages between 10 and $100 \mathrm{kV}$. Physics in Medicine and Biology 29 (5): 579-591, 1984.

GROSSWENDT B. Dependence of the photon backscatter factor for water on source-tophantom distance and irradiation field size. Physics in Medicine and Biology 35 (9): 1233-1245, 1990.

HAMMERSTEIN R., MILLER D.,WHITE D., MASTERSON M., WOODARD H.; LAUGHLIN J. Absorbed radiation dose in mammography. Radiology 130: 485-491, 1979.

HAUS A., Historical technical developments in mammography. Technology in cancer research \& treatment (1):119-126, 2002.

HARRISON R.M. Backscatter factors for diagnostic radiology (1-4 mm Al HVL). Physics in Medicine and Biology 27 (12): 1465-1474, 1982.

HENDRICK E. R. Standardization of image quality and radiation dose in mammography. Radiology 174: 648-54, 1990.

INTERNATIONAL ELECTROTECHNICAL COMMISSION. International Standard 1066. First edition, 1991.

INSTITUTE OF PHYSICAL SCIENCES IN MEDICINE. The commissioning and routine testing of mammographic X-ray system. Report $N^{\circ} 59$ (2a edição), IPSM, York, 1994.

JOHNS, H.E., CUNNINGHAM, J.R. The Physics of Radiology. Springfield: Charles C. Thomas, 1983.

KLEVENHAGEN S.C. Experimentally determined backscatter factor for x-rays generated at voltages between 16 and $40 \mathrm{kV}$. Physics in Medicine and Biology (36):1871-1872, 1989. 
KLEVENHAGEN S.C., AUKETT R.J., BURNS J.E., HARRISON R.M., KNIGHT R.T., NAHUM A.E. Report of the IPSM working party on low-and medium-energy x-ray dosimetry. Physics in Medicine and Biology (36):1027-1038, 1991.

KRAMER R., DREXLER G., PETOUSSI-HENSS N., ZANKL M., REGULLA D., PANZER W. Backscatter factors for mammography calculated with Monte Carlo methods. Physics in Medicine and Biology (46):771-781, 2000.

LESTER R. G. Risk versus benefit in mammography. Radiology 124:1, 1997

McKINLAY, A.F. Thermoluminiscent Dosimetry. Great Britain, Adam Hilger Ltd, Techno House, Redcliffe Way, Bristol.

MINISTÉRIO DA SAÚDE - SECRETÁRIA DE VIGILÂNCIA SANITÁRIA. Diretrizes de proteção radiológica em radiodiagnóstico médico e odontológico. Portaria N.453. Brasília, DF: Diário Oficial da União, 2/6 1998.

MINISTÉRIO DA SAÚDE - SECRETÁRIA DE VIGILÂNCIA SANITÁRIA. Resolução Nacional- RE $\mathbf{n}^{\mathbf{0}}$ 1016, 03 de abril de 2006.

MINISTÉRIO DA SAÚDE. AGÊNCIA NACIONAL DE VIGILÂNCIA SANITÁRIA(ANVISA). Radiodiagnóstico Médico: Desempenho de Equipamentos e Segurança /Ministério da Saúde, Agência Nacional de Vigilância Sanitária,104 p. (Série A. Normas e Manuais Técnicos). Brasília: Ministério da Saúde, 2005.

NOGUEIRA, M. S. "Determinação de Fatores de Conversão de Kerma no ar e de Fluência para o Equivalente de Dose Ambiental para Raios -X Gerados no Intervalo de 50 kVp a 125kVp”. Tese (doutorado), CNEN/IPEN,1997.

NARIYAMA N., TANAKA S., YOSHIZAWA M., HIRIYAMA H., BAN S., NAKASHIMA H., NAMITO Y., NAKANE Y. Responses of LiF to $10-40 \mathrm{keV}$ monoenergetic photons from sincrotón radiation. Radiation Protection Dosimetry 49 (4): 451-457, 1993.

OLAYA D. H., SOTO G. E. Estudio de la dependencia geométrica durante el posicionamiento de material termoluminiscente en equipos lectores TLD. Universidad Pedagógica y Tecnológica de Colombia - Escuela de Física, 2006. 
SCHAUERT D.A., CASSTA J.R., KING J.J. A comparison of measured and calculated photon backscatter from dosemeter calibration phantoms. Radiation Protection Dosimetry 88 (4): 319-324, 2000.

SQUAIR P.L. "Caracterização de um dosímetro individual de extremidades para avaliação do equivalente de Dose Pessoal, $\mathrm{HP}(0,07)$, em campos de radiações $X$ e Gama". Tese(Mestrado). Escola de Engenharia da Universidade Federal de Minas Gerais - Belo Horizonte, 2008.

STANTON L., BRATTELLI S.D., DAY J.L. Measurements of diagnostica x-ray backscatter by a novel íon chamber method. Medical Physics 9 (1): 121-130, 1982.

STANTON L., DAY J.L, BRATTELLI S.D., LIGHTFOOT D.A. Comparison of ion chamber and TLD dosimetry in mammography. Medical Physics 8(6):792-798, 1981.

STANTON L., VILLAFANA T., DAY J., DAVIS A.L. Dosage Evaluation in Mammography. Radiology 150: 577-584, 1984

TRAUB, R.J., McDONALD, J.C., MURPHY, M.K. Determination of Photon Backscatter from Several Calibrations Phantoms. Radiation Protection Dosimetry 74: 13-20, 1997.

VELBECK K.J., ZHANG L., GREEN R., TOMLINS P. Performance and test results of Harshaw pelletised LiF:Mg, Ti TLD material. Radiation Protection Dosimetry 84(1-4): 243-246, 1999.

VIEGAS C.C.B. "Dosimetría in vivo com uso de detectores semiconductores e termoluminescentes aplicada ao tratamento de câncer de cabeça e pescoço". Tese (Mestrado), Universidade Federal de Río de Janeiro, 2003.

ZOETELIEF J., AALBERS A.H., BEENTJES L.B., BROERSE J.J., JULIUS H.W., ZUUR C. Dosimetric Aspects of Mammography. Netherlands Commission on Radiation Dosimetry. Report 6, 1993 